\title{
Disability Friendly Virtue Ethics
}

\author{
by \\ Rebecca Robb
}

A thesis submitted to the Faculty of Graduate and Postdoctoral Affairs in partial fulfillment of the requirements for the degree of

Master of Arts

in

Philosophy

Carleton University

Ottawa, Ontario

(C) 2018 


\begin{abstract}
Disability friendly virtue ethics calls for an accessible world. With the help of Aristotle I argue that to be fully virtuous one must be able to flourish. I also argue that all disabled people have the potential to flourish and be fully virtuous, including those with profound intellectual impairments. I point to systems of oppression and discrimination against disabled people and argue they are wrong in part because they block flourishing. By imagining a world where disabled people, and all people, can flourish I identify seven virtues that would most encourage removal of barriers to the flourishing of people with disabilities. Disability friendly virtue ethics is grounded in Aristotlian virtue ethics and includes insights from disability theory and activism.
\end{abstract}


This thesis is dedicated to the memory

of my grandfather Frederick Burke Cahill, who taught me to question everything. 


\section{Acknowledgements}

I'm grateful to my mother Rose Mariana Robb for her wisdom and unstinting support. Thank you for introducing me to philosophy and the disability movement, and for encouraging me to take pride in myself as a disabled person.

I'd like to express my deep gratitude to Dr. Margaret Cameron who taught me at the University of Victoria and first sparked my admiration for Aristotle.

I am especially grateful to Charles Mills for his advice and encouragement.

This thesis would not have been possible without the guidance and encouragement of my supervisors Dr. Christine Koggel and Dr. Annie Larivee. Thank you both for being so generous with your time and knowledge.

A special thank you to Sandy Kirkpatrick and Kristopher Waddell of Carleton University, who were always there for me when I needed anything.

I'd like to thank my grandmother Helen Cahill and her care team. My grandmother for her kindness and sense of humour, and her care team for cheering me on. Thank you Ashley, Ginny, Grace, Jade, Marianna, Sally, Sam, Tanya, Thurza and Tracy.

Thank you to my Uncle Ian for his helpful critiques at the early stages.

I'd like to thank my Aunt Joan and Uncle Ed for their love and support.

Thank you to my Dad for his generous help as I headed to grad school.

I'd also like to acknowledge the contribution of my Carleton cohort, Michael, Danielle, Miles, Nyx, Brandon, Courtenay and Brian, who all insisted that I abandon my original thesis idea (what is a chair?) in favour of disability friendly virtue ethics. Thank you.

I am grateful to my Ottawa housemates Lisa and Olive and my friend Sasha for listening and listening, and understanding, as I thought out my thesis topic.

I'd like to thank my many friends and colleagues from the disability advocacy group, Access UVic, for the opportunity to mature and thrive in a joyful crossdisability culture, especially Orion, Scotty, Tanja, Jim, Scott, Erin, David, Erica W., Erica V., Trevor, Justin, Wendy Marie, Rachel, Rachael, Jose, Bartek, Julia, Elizabeth L., and Elizabeth S.

I'd like to thank the Victoria chapter of the Canadian Federation of the Blind for their warm welcome and fellowship over many years. 
A special thank you to David J. A. Foster for last minute help with this work.

I am grateful to my assistant, Olivia Brown for her cheerful enthusiasm and her high tolerance for last minute revisions. Thank you.

Last but not least, thank you to Doug Bowes of SET BC for teaching me to read and write with computer software so that my education was possible. 


\section{Table of Contents}

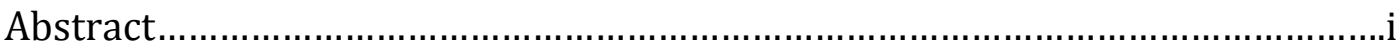

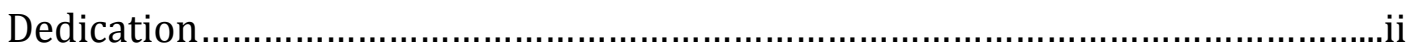

Acknowledgments.........................................................................

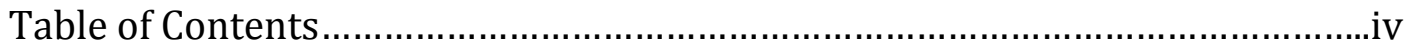

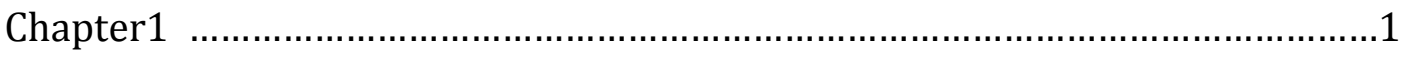

Section 1:

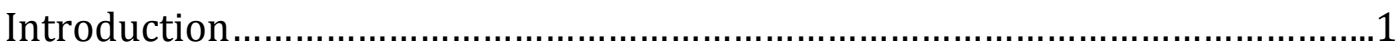

Section 2:

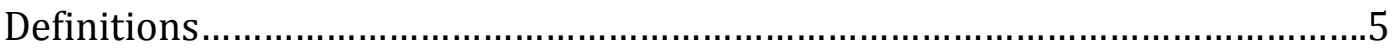

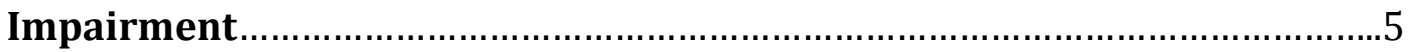

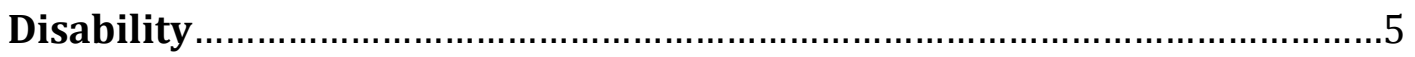

A Philosopher's Definition of Disability .....................................................

Social Model Definitions of Disability .....................................................

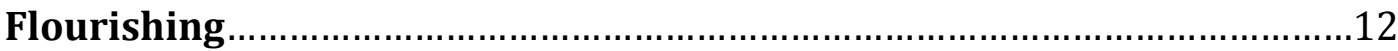

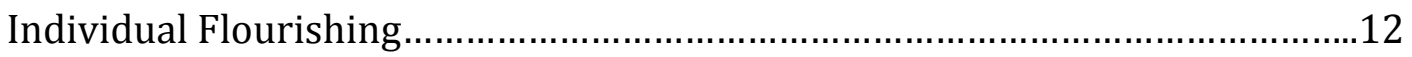

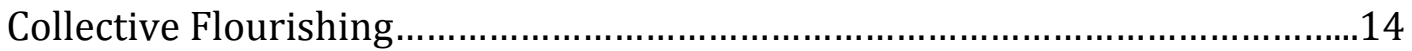

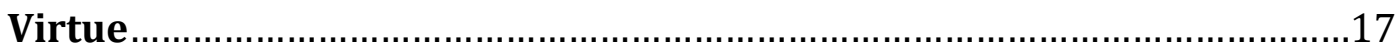

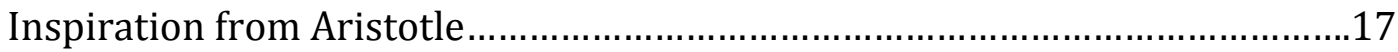

Aristotle's Mean: Why is it Golden, for Disabled People and Others.................19

A Couple Caveats: Where my Definition of Virtue Differs from Aristotle's.......23

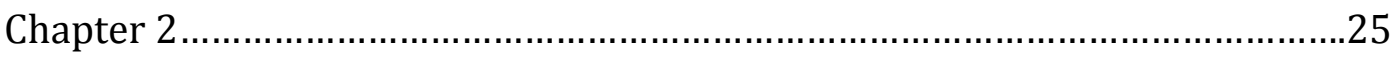

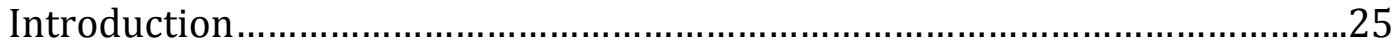




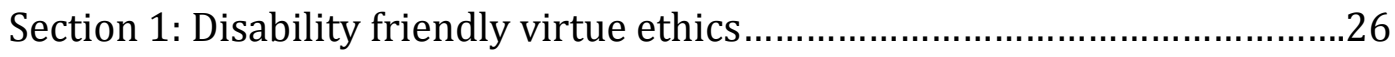

What We're Up Against: Blocks to flourishing as Disabled People...................29

Expanding on Aristotle: The Vices of Oppression..............................................33

Section 2: Seven Disability Friendly Virtues.....................................................34

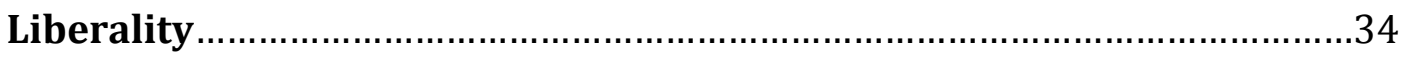

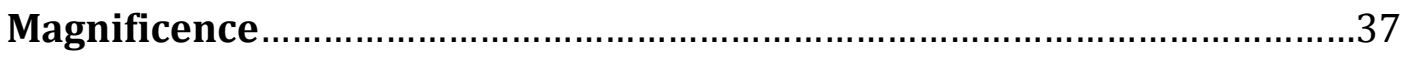

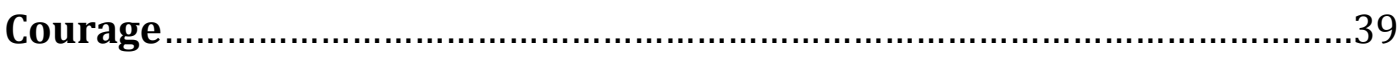

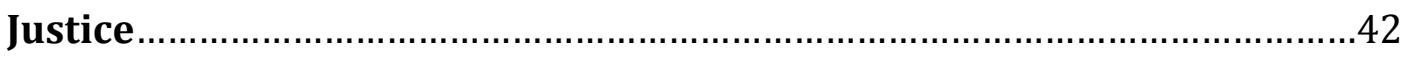

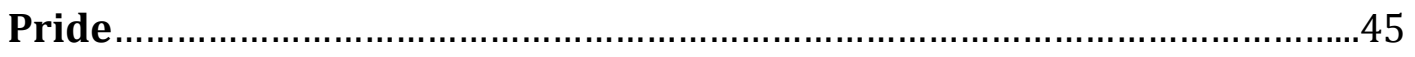

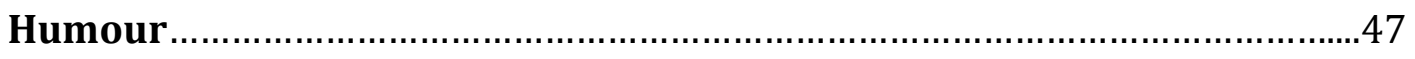

Trust

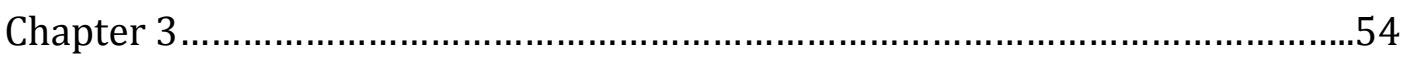

Section 1: Flourishing with disabilities? You bet!.....................................................54

Flourishing with Intellectual Impairments.....................................................54

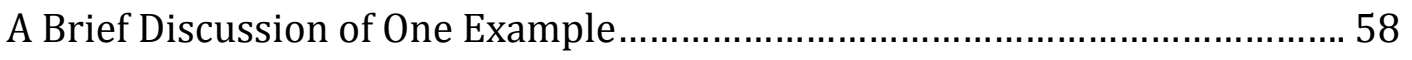

Inclusion: A Gateway to Flourishing, at Least in Theory ..................................60

So Some Lives are Not Worth Living? ............................................................... 61

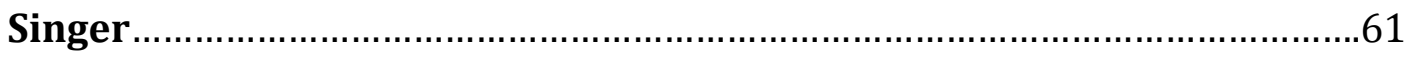

R.G. Frey

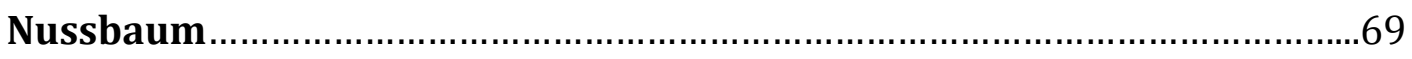

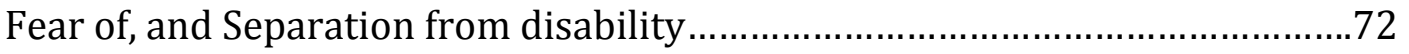

Section 2: Virtue with Disability, It Can be Done...............................................73

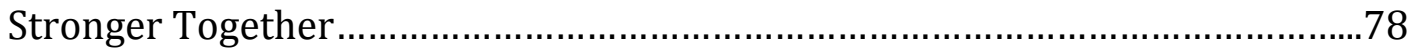


Inclusive Metaphysics Provides a Foundation for Inclusive Ethics....................79

Holding Out for Heroes.............................................................................. 81

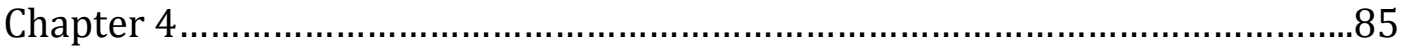

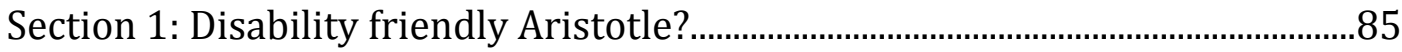

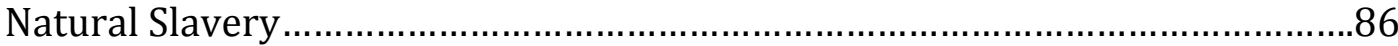

How Should We Respond to Aristotle’s “Natural Slavery”?......................................89

Aristotle and the Exposure of Deformed Infants..........................................91

Interpreting "Let There Be a Law that no Deformed Child Shall Live"..............94

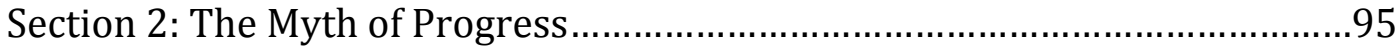

Modern Equivalents to the Exposure of Disabled Infants................................96

History of Prejudice against Disability, over Centuries. Fear Builds...............100

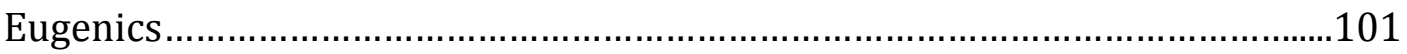

Infanticide in Ancient Greece, the View from Archaeology............................103

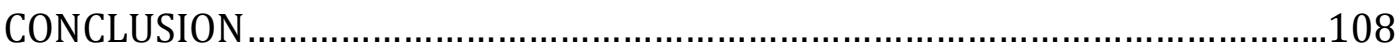

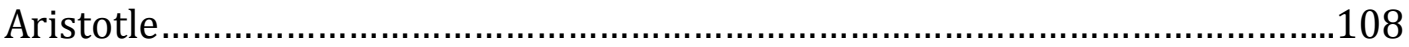

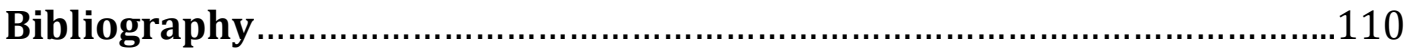




\section{Chapter 1}

"Steer that ship out beyond the surf and spray..." (Nicomachean Ethics 1109a30; hereafter cited as $N E$ )

\section{Introduction and Definitions}

\section{Section 1: Introduction}

The aim of this work is to argue that Aristotelian-inspired virtue ethics, when combined with modern disability theory, calls for an accessible world and therefore requires the removal of barriers to flourishing for people with disabilities. In the following chapters, I will argue that blocking disabled people from flourishing is wrong (in Aristotelian virtue ethics terms 'vicious'); it is bad for the characters of individuals and for society as a whole.

I have been involved in disability advocacy since childhood when my family and I launched a successful human rights case, Robb v. St. Margaret's School, and the experience stuck with me. Growing up, I stayed involved in the disability movement and as a teenager participated in the World Summit of Disabled Peoples International in 2005 in Winnipeg, Canada, a global organization of disabled disability advocates. In microcosm, this conference showed me what a society free of discrimination on the basis of disability could look like. The conference was vibrant and packed and although it only lasted for a few days, I got a sense of what a societal model that did not discriminate against disability would look like and a glimpse of the virtues of disability culture in action. From the very moment of registration, humour, openness, tolerance, flexibility, trust and pride were on display. Does it maybe take you five minutes to introduce yourself? Haste is for suckers. You have an assistant? Cool, but unremarkable. Speak with a computerized voice? Neat! Or, as in my 
case, can't read the program? A digital copy is on the way! No one even blinked; I had never had anything like that reaction before.

My new acquaintances had futuristic, assistive devices and gracious helpful personnel who stood courteously by their employers like celebrity bodyguards. For once, my disability was a mildly interesting characteristic, neither intrinsically negative nor positive. There was not a hair of judgment nor a whisper of condescension. For a few days, it felt to me as though a little polis had formed in the middle of Winnipeg; disabled people en masse who, to my joy, were cool, funny and capable of handling anything. Disability was the norm: hotels and conference centres full of people with unusual bodies, power wheelchairs, guide dogs, interpreters and personal assistants. With numbers on our side, condescending attitudes lost their sting; acceptance, automatic accommodation and a breezy cosmopolitanism were suddenly standard. The daily slog of negotiating for accommodation was gone. The idea that being disabled was uncool or pitiable nowhere to be seen.

At the conference's concluding dinner, I sat with a group of new friends: a disability advocate from Britain, an Oxford educated presenter from India, her poised and witty assistant, and a Russian conference attendee, with myself and my mother rounding out the company. I was excited to be included. Our group secured a table intended for a nondisabled group of bankers by the cunning expedient of slipping the assigned seating card under a napkin. ("That's so Russian," declared our Russian friend.) The bankers came in minutes later, radiating condescension, looking in vain for their assigned table. Disabled people: one. Bankers: zero. When our waiter could not grasp why someone might need their glass of wine in a sippy cup, the group's unsuccessful efforts to restrain giggles produced a bottle of wine at lightning speed. 
In retrospect, this evening of laughter and fun had political and ethical overtones; the virtues and political priorities of disability culture were in evidence through practical action. For example, when I saw that needing to drink wine out of your own adapted cup was accepted, this made me feel at home and at ease with my need for help reading the menu. The need for flexibility was taken for granted, an automatic courtesy allowing for trust and openness amongst the company. According to Aristotle, if one really wants to be ethical, theorizing is not enough. One must cultivate the virtues in oneself and achieve them by living them out: that is the true meaning of virtue (NE1105b). Disability culture, in my experience, shares this pragmatism. Flexibility was an enjoyable part of the evening, not a burden. For Aristotle, virtue is like this: if you're doing it right, it will be a pleasure. "The man who does not rejoice in noble actions is not even good; since no one would call a man just who did not enjoy acting justly, nor any man liberal who did not enjoy liberal actions; and similarly in all other cases" (NE 1099a16-18). If, in order to truly achieve virtuous action you need to enjoy being virtuous, then virtue needs to flow from your character.

It seemed entirely natural for our group to turn our waiter's ill-concealed nervousness at being in the company of so many disabled people into something funny; there was a wellspring of good humour which bubbled up among us. It was infectious and joyful. I think our mirth drew our waiter into our circle, allowing him to see that disabled people are not so scary after all, and by the time the dinner was breaking up he was in on the joke. Humour is often used consciously in advocacy work by many groups to sharply unearth the absurdities of prejudices. In disability culture, it can be sardonic, but I have found the humour tends to be gentler when non-disabled friends are present, a way to bridge the gap between disabled and nondisabled, a way of saying, "Here we all are and don't you 
think this is funny too?"

Pride too was on display, its effect less gentle. It was pride in ourselves, which allowed us to take precedence over the bankers and, for a moment, everything that financial power stands for, all the insistent power of capital. For Michael Oliver, a preeminent disability scholar, a wholeheartedly capitalist society and a fully accessible society cannot coexist, as capitalism's insistent demand for productivity does not jive well with the realities of impairment. Some impairments can mean that conventional productivity or any productivity is impossible. Pride makes visible the tyranny of productivity. It is easy to see the tyranny of productivity for disabled people. It becomes evident when one cannot be productive or as productive as others, but nevertheless knows one's own value. Oliver puts it like this: "Expecting severely disabled people to be as productive as non-disabled people is one of the most oppressive aspects of capitalist society" (Oliver 2009, 123). Disabled people are in an excellent position to question the common half-conscious assumption that worth and productivity are identical. The pride at our table was a very Aristotelian pride too: dignified, upright, unapologetic, the pride of a waving banner, not of a pat on the head or limp handshake, pride uncontaminated by pity, just as Aristotle would have it (NE 1123a351125a16).

In my experiences at the World Summit of Disabled Peoples International, I believe we can see parallels between Aristotelian virtue ethics and the virtues of disability culture in action. The World Summit allowed a window into an accessible world; barriers that are often placed in front of disabled people were not present, allowing for flourishing, virtue, and Aristotelian true happiness. At the Summit, I was amongst allies in a friendly, accessible environment. As a young person I was taught by example what I would argue are 
virtues particularly valuable to many disability advocates in a very Aristotelian way. I was taught to enjoy taking pride in being a disabled person, to enjoy the openness and trust that can come with being disabled. I learned to value the reality that all people need support and that this is not shameful but a source of groundedness and strength. At the Summit, and especially at the final dinner amongst allies, in a friendly accessible environment, I was, along with my companions, able to flourish. It was not the complete flourishing that Aristotle considers the aim of human life (NE 1098a16-20) but it was, briefly, close to that. I will argue that Aristotelian virtue ethics can give a robust ethical foundation for disability friendly virtue ethics.

\section{$\underline{\text { Section 2: Definitions }}$}

In this section I will explore and define 'impairment', 'disability', 'flourishing' and 'virtue' and explain why I use the terms as I do.

\section{Impairment}

The Oxford English Dictionary (OED) defines impairment as "any

diminution in quality or strength; more specifically, any diminution in the quality or strength of physical or psychological functioning in some specified domain". This is a useful definition, but the Encyclopedia of Disability presents a more complicated story:

Impairment is one of the most contested and complicated terms in disability studies, second only to disability itself in terms of multiple definitions and theoretical arguments made around its meaning and significance in the experience and scholarship of the body. (Albrecht 2006, p. 920-922)

The entry goes on to clarify that within contemporary disability studies many 
understandings of impairment are at present being debated, including impairment as a neutral characteristic, impairment as itself a social construction and impairment as a medically imposed label that may be suspect.

I understand impairment as a neutral lack of a capacity, or a set of capacities, amongst persons. I draw on the $O E D$ and early social model understandings of impairment.

The origins of impairment as a term in disability studies may be positioned in the development of documents by such organizations as the Union of the Physically Impaired Against Segregation (UPIAS) in Great Britain and the World Health Organization (WHO). In 1976, UPIAS offered its own definitions: ...impairment refers to "lacking part or all of a limb, or having a defective limb, organ or mechanism of the body"; disability refers to the social oppression (whether due to stigma or to restrictions) imposed on people with impairments. The important distinction for UPIAS lies in location: impairment is located in the body; disability is located in society or culture. (Encyclopedia of Disability, p. 921)

It was this understanding of impairment which was adopted by Michael Oliver and other disability scholars in the 1970's to form the core insight of the social model of disability. While the distinction between a neutral impairment and a socially constructed disability is conceptually clear and tremendously useful, there is no bright line between one's impairment and one's disability in lived experience.

I think the social model is best understood as a conceptual tool. It should not imply that all people experience their physical characteristics (including any impairments) as neutral. Because the words impairment and disability are interchangeable in common usage, I use both terms.

\section{Disability}

For my definition of disability, I borrow from the United Nations (hereafter UN) Article 1 of the UN Convention on the Rights of Persons with a Disability: 
Persons with disabilities include those who have long-term physical, mental, intellectual or sensory impairments which in interaction with various barriers may hinder their full and effective participation in society on an equal basis with others. (https://www.un.org/devlopment/desa/disabilities/convention-on-the-rights-ofpersons-with-disabilities.html\#Fulltext (article one)

I find this definition clear, practical and useful. Additionally, the UN's definition is part of a larger project, aiming to promote the flourishing of disabled people and discourage discrimination on the basis of disability. I share these aims. To explain further why, in my view, this definition is the best for my purposes, I will briefly explore a contrasting philosopher's definition of disability as well as a social model definition.

\section{A Philosopher's Definition of Disability}

Defining terms in philosophy is surprisingly challenging, as Socrates has taught us. The meaning of familiar words anyone would feel they could define can dissolve under close examination. In addition, it matters who is defining disability and for what reason. For instance, are we examining a definition of disability created by disabled people themselves or by those with power over them? A legal definition designed to establish who is entitled to disability benefits? A straightforward dictionary definition? A definition conceived as a tool for advocacy? One to evoke pity and encourage charity? A medical definition?

In The Minority Body, Elizabeth Barnes teases out a solid definition of disability, motivated in part by a philosopher's desire for precision and intellectual rigour and in part by recognition of the politically charged terrain. According to Barnes, "disability is all and only the things that the disability rights movement ought to consider as things they are promoting justice for-it is rule-based solidarity among people with certain kinds of bodies" (Barnes 2016, p. 46). 
Her position is that physical disability is a social construction and a physical reality; physical disability consists in having the type of body that is included in the range of types of body for which the disability movement is seeking justice. But, crucially, the disability movement is only compelled to seek justice for people with this range of bodies because society has historically and presently continues to discriminate against them (Barnes, 29$33)$.

Here's the idea, in a nutshell. A collection of people got together and identified a form of group solidarity. Although they had a strikingly heterogeneous range of physical conditions, they perceived a commonality in how those physical conditions were stigmatized, how people treated them because of those physical conditions, how those physical conditions made it difficult to access public spaces, to complete everyday tasks, to get adequate healthcare, get full-time employment and benefits, etc. And so despite having very different bodies, it made sense to think of their experience of their bodies as having something in common, and it made sense to think of themselves as working toward a common goal. (Barnes, $p$. 32)

In general, the Disabled People's Movement and Disability Studies understand disability as neither intrinsically a bad thing, nor inherent to the individual. Elsewhere, as Barnes makes clear, disability is often defined as both intrinsic to the individual and by definition, if not tragic, then at least a hindrance to overall well-being. Barnes bridges this gap by developing a clearheaded and respectful definition of disability that describes disability as both a physical feature of people's bodies and a social construction. Disability is seen differently inside and outside of the Disabled People's Movement and this divide extends to philosophy:

There is a massive disconnect between the way disability is understood in the disability rights and disability pride movements and the way disability is understood within analytic philosophy. The former see being disabled as primarily a social phenomenon - a way of being a minority, a way of facing social oppression, but not a way of being inherently or intrinsically worse off. (Barnes, p. 1) 
I am sympathetic to Barnes' definition of disability, yet I think it is not quite right. First, Barnes only defines physical disability; I am interested in defining both physical and mental disability. Second, although Barnes' definition is philosophically unassailable in a way the United Nations is not, her definition lacks the United Nations' explanatory power. If one is not familiar with the Disabled People's Movement or its aims, Barnes does not make it clear to you what disability is. The UN's definition conveys a clear sense of disability, whether or not one is familiar with the Disabled People's Movement.

\section{Social Model Definitions of Disability}

The social model of disability was first articulated by the disability scholar Michael Oliver in the early 1980's and remains influential. The central insight of the social model is that people's bodies are not the source of disability; instead, disability (in so far as it is a disadvantage) is a creation of systemic discrimination, faced by people with impairments. A distinction between disability and impairment is a crucial part of the social model. Within the social model, impairments (i.e. physical features such as being an amputee) are understood as neutral characteristics. Of the social model of disability, Oliver says, "This turned the understanding of disability completely on its head by arguing that it was not impairment that was the main cause of the social exclusion of disabled people but the way society responded to people with impairments" (Oliver, 43). Most definitions of disability used in Disabilities Studies today descend from or respond to the social model of disability.

I am sympathetic to the social model, but do not think it is a definition of disability in its own right. According to Oliver, the social model of disability is not precisely a definition or theory of disability, but a way of reconceptualizing disability for practical purposes; it is 
a tool for disability advocacy rather than just a definition. Responding to the critique that the social model of disability is not a strong theory or definition of disability, Oliver notes:

The final criticism of the social model is that it is inadequate as a social theory of disablement. Now, the problem with this is that I do not think that those of us involved in the early discussions around the social model ever claimed that it was equivalent to a theory of disability. Indeed, most of us explicitly said these theoretical debates still needed to take place. (Oliver, p. 49)

Oliver originally contrasted the social model of disability with a single alternative model:

the individual model, on which disability is seen as a personal tragedy (Oliver, p.42).

Although I thoroughly agree with the social model as an approach to disability, theory, and advocacy, in terms of definition, in my view the UN's greater explanatory power wins out here.

A final advantage of "disabled person" is that it echoes the social model. The phrase "disabled person" suggests that an individual is being disabled by something; in my and Oliver's view this is large-scale societal discrimination. However, I think both terms can be effective, and I use both.

There is also a debate concerning how to refer to disabled people as a group.

Proponents of "people first" language prefer not to place the disability or term disabled before the person. The brief article "People-First Language" by Dr John Harrington gives a clear sense of the people-first ethos.

I hope these examples are enough to convince you that people-first language does matter. Although it requires a few more words and a few more seconds to communicate the same information, it puts the human being ahead of the condition, which is where we deserve to be. (Harrington 2008, p. 305)

Although the impulse behind person-first language is laudable, I think it may become overly restrictive at times for some groups such as the blind or the Deaf, for whom shared cultural identity and/or linguistic identity are particularly important. It 
should be noted that many who identify as Deaf, reject the label disability, which remains highly stigmatized. Barnes suggests that they "take on board the common assumption that disability is bad, but want to argue that deafness is not bad. And this sometimes results in claims like 'Deafness is not a disability."(Barnes, p.22) Terms like "the blind" or "the Deaf" are common and valued expressions of cultural identity. Consider this passage from the mission statement of the Canadian Federation of the Blind, Canada's foremost advocacy organization of the blind:

The Canadian Federation of the Blind came together to fight the social and economic inequality of blind people in Canada. We came together to celebrate the achievements of blind people. If blind people have proper training, a positive attitude, and genuine opportunity, we believe blindness need not be a handicap, but is just one among myriads of normal characteristics. (http://www.cfb.ca)

There is not a broad consensus on the acceptability of the term "the disabled" amongst all disabled people. However, I would argue that terms like the disabled, the blind or the Deaf help to make it clear that the disabled are a potentially cohesive group and, especially in the case of the Deaf, a united people with their own distinct language and culture. Terms like the Russians, the Chinese or the Irish are considered respectful ways to refer to a nation or people; such phrases emphasize collective identity, as does the term the disabled in my view. To me it is not clear that "the blind" reduces a person to their impairment when we speak easily enough of the rich, or the strong. Using the term disabled people is also a way to resist societal pressure to separate disabled people from collective political power. I like to think disabled people as a people, could become a force to be reckoned with. For these reasons, I occasionally refer to both disabled people, and the disabled.

\section{Flourishing}


I define flourishing as living well and virtuously over a complete lifetime in an accessible society which allows for the flourishing of disabled people and all people. I assume that living well and being virtuous vary from person to person and society to society. However, I do assert that there will be a way for all people to flourish. I suggest it is possible to flourish both as an individual and as a collective or society. In my view, it would be ideal to flourish individually in a society that is itself flourishing. I believe these types of flourishing cannot be completely separated since individuals flourish in societies.

\section{Individual Flourishing}

For individual flourishing, my main resource is Aristotle. Aristotle believes there is a distinctively human way to live well. He calls such a good, complete human life one of eudaimonia, which is often translated as happiness or flourishing. I derive my own sense of individual flourishing in large part from Aristotle's definition of eudaimonia. Excellence (i.e. moral virtue) is, for Aristotle, both definitive of a good human life and a description of a truly happy life. Importantly for Aristotle, happiness (or eudaimonia) is not a momentary emotional state, but something much deeper and more complex; in order to truly flourish one must have the chance to do so throughout a complete life. As Aristotle says, "For one swallow does not make a summer, nor does one day; and so too one day, or a short time, does not make a man blessed and happy" (NE 1098a20). Flourishing, or failing to do so, is a lifelong affair; to be happy is to be flourishing, leading a good life well. "Another belief which harmonizes with our account is that the happy man lives well and fares well; for we have practically defined happiness as a sort of living and faring well" (NE 1098b21). For Aristotle, flourishing or living well is the purpose of life for human beings. "We state the 
function of man to be a certain kind of life, and this to be an activity or actions of the soul implying a rational principle, and the function of a good man to be the good and noble performance of these" (NE 1098a13-14). Aristotle sums up, saying, "Human good turns out to be activity of soul in conformity with excellence" (NE 1098a15-16).

Aristotle is clear, and I agree, that flourishing is not just about being a good person. It also requires resources such as the basic necessities of life, decent social position, friends and freedom from calamity.

Yet evidently, as we said, it needs the external goods as well; for it is impossible, or not easy, to do noble acts without the proper equipment. In many actions we use friends and riches and political power as instruments; and there are some things the lack of which takes the lustre from blessedness, as good birth, satisfactory children, beauty; for the man who is very ugly in appearance or ill-born or solitary and childless is hardly happy, and perhaps a man would be still less so if he had thoroughly bad children or friends or had lost good children or friends by death. As we said, then, happiness seems to need this sort of prosperity in addition; for which reason some identify happiness with good fortune, though others identify it with excellence. (NE 1099a31-b8)

Disabled people, like Aristotle's "ugly man," are often put in positions where flourishing is not a possibility. Aristotle makes it clear that much more is required to live well than a cando attitude. Even though Aristotle does not object to categorizing people as ugly, I would suggest Aristotle calls out prejudice against people with unusual bodies despite himself. By pointing out that being ugly (or, as I would say, being perceived as ugly) blocks your chances to flourish, Aristotle gets to the bottom of what is wrong with labeling people as ugly: it blocks flourishing. Because, in an Aristotelian view, flourishing is important, there is, I would suggest a clear incentive to go to work dissolving discriminatory beauty norms that may contribute towards blocking the flourishing of disabled people in many societies.

Although in the main, I agree with Aristotle's definition of flourishing, there are a couple points on which I disagree with him. First, I disagree with his partial equation of 
humanity with intellectual ability. For Aristotle, part of what it means to be human is to exercise one's rational capacities; I do not suggest that one must have any specific level of intellectual ability in order to flourish or to be human. Aristotle's tight focus on intellect is a problem which many philosophers share. In our love for learning, knowledge and the life of the intellect we tend to denigrate all other aspects of human life. Second, although I agree with Aristotle that the flourishing life is a good human life, I do not share his confidence that flourishing is the purpose of human beings in the existential sense; this claim seems to me unverifiable.

One last note on individual flourishing: in my view, what it means to flourish as a person is distinct from flourishing as a plant or animal. I do not mean to imply that animal and plant flourishing is not also important; I do not suggest human beings are better than animals and I acknowledge that interaction with the natural world may be part of flourishing for people. However, I plan only to discuss the flourishing of people. In my view comparing or equating human and animal flourishing can dehumanize disabled people by implying that disabled people flourish (if they can do so at all) in the manner of animals. I therefore will assume that animal and human flourishing are distinct.

\section{Collective Flourishing}

In my view, the flourishing of disabled people is connected to the flourishing of all and a society that allows disabled people to flourish would be a good place for everyone. Michael Oliver, in Understanding Disability, makes a similar point as part of his critique of capitalism and his case for a truly inclusive welfare state:

In our view disabled people and their organizations have taken the first steps and initiated a glimpse of that vision of how the world ought to be. In fact, for us, 
disabled people have no choice but to attempt to build a better world because it is impossible to have a vision of inclusionary capitalism; instead we need a world where impairment is valued and celebrated, and all disabling barriers are eradicated. Such a world would be inclusionary for all and it is up to everyone, but especially those involved in the development and implementation of social policy both planners and practitioners - to nurture it and help make it a reality. (Oliver, p. 29)

Michael Oliver's move here (and mine as well) is to put disability at the center of the good life for all. Oliver acknowledges the complexities involved in determining what the good life might be, but argues the good society is one where everyone could have a good life, or flourish.

Although versions of the good society vary, for us, it is a world in which all human beings, regardless of impairment, age, gender, social class or minority ethnic status, can coexist as equal members of the community, secure in the knowledge that their needs will be met and that their views will be recognized, respected and valued. (Oliver, p. 130)

When I say that flourishing is to live well in an accessible society, this is the kind of accessible society I have in mind. Although we are not there yet, with this goal in mind, 'flourishing' may become an option for more people in their lives. As Aristotle says, "Shall we not, like archers who have a mark to aim at, be more likely to hit upon what we should?" $(N E$ 1094a25)

In my experience, accessibility is sometimes seen as a frill or an add-on: great for those who need it, but not important for everyone. I suggest a truly accessible society would allow everyone to flourish. According to the online Oxford Dictionary of Occupational Science and Occupational Therapy, the word 'accessibility' simply means: "The extent to which a space or resource can be accessed by those who need to do so." (Oxford, 2017) The Encyclopedia of Disabilities' more robust definition of accessibility includes this gem:

"Accessibility is not an act or a state but a liberty to enter, to approach, to communicate 
with, to pass to and from, or to make use of a situation.” Everyone can benefit from smooth access to what they need.

I would argue that a hallmark of accessibility is that it tends to be valuable to more people than one might expect. Addressing the value of a barrier-free environment for all, while critiquing excessive focus on physical rehabilitation for its own sake, Oliver says: "To put it simply, providing a barrier-free environment is likely to benefit not just those with a mobility impairment but other groups as well (e.g. mothers with prams and pushchairs, porters with trolleys)...” (Oliver, p. 46). Any nondisabled readers who have used a curb cut while biking or pushing a stroller may agree.

It is widely recognized that accessibility features have a tendency to be useful to many nondisabled people; this has become known as the "curb cut effect". In Angela Glover Blackwell's article "The Curb Cut Effect”, she defines this effect in an American context and argues for its value. She notes that in 1970's America when the first hard-won state-mandated curb cuts were put in place, many people beyond the expected group of wheelchair users benefited as well:

Then a magnificent and unexpected thing happened. When the wall of exclusion came down, everybody benefited - not only people in wheelchairs. Parents pushing strollers headed straight for curb cuts. So did workers pushing heavy carts, business travelers wheeling luggage, even runners and skateboarders. A study of pedestrian behavior at a Sarasota, Fla., shopping mall revealed that nine out of ten "unencumbered pedestrians" go out of their way to use a curb cut. As journalist Frank Greve has noted, the barricades stormed by disabled advocates in Berkeley 40 years ago were a few inches high, 'yet today millions of Americans pass daily through the breaches.' (Blackwell 2017, 28)

I suggest that accessibility contributes to the flourishing of all.

There does not yet to my knowledge exist a society where full accessibility is the norm; my definition of disability is aspirational, even utopian. Yet I do not think that this 
makes it unrealistic as there is a great tradition of utopian thought in philosophy, stretching all the way back to Plato's Republic. Oliver gives a nod to the valuable part utopian thinking can play in building the world we want to become reality: "As Oscar Wilde so cogently pointed out over a century ago in The Soul of Man Under Socialism (first published in 1890): 'a map of the world that does not include Utopia is not even worth glancing at... Progress is the realization of utopias' (Wilde, p. 1090)" (Oliver, p. 122).

Although Aristotle's definitions of a good society are very distinct from Oliver's, they do share one element: both wish for a society in which citizens can live well and in which society itself pushes people towards the good life.

\section{Virtue}

By "virtue," I mean to take pleasure throughout life in living and acting morally in a way that encourages one's own flourishing, and the flourishing of others. Virtue is not static, but shifts based on the virtuous person's situation, capacities and/or disabilities. Being virtuous is a learned skill.

\section{Inspiration from Aristotle}

I am a virtue ethicist in Aristotle's sense: I think ethics is about living well and having a good character rather than exclusively focused on working out what action is right in a specific situation. In an Aristotelian view, if you're a virtuous person in a workable situation, right action will come naturally, even when faced with challenging situations. According to Paula Gottlieb, in her book The Virtue of Aristotle's Ethics, the term "virtue ethics: was introduced in the 1960's to refer to an ethical approach that not only makes 
virtue of character primary but also marks a distinctive and superior alternative to prevailing Utilitarian and Kantian approaches" (Gottlieb 2009, p. 4). Briefly, while Utilitarians are interested in the goodness of states of affairs or the consequences that flow from particular actions and Kantians concentrate on duties the virtue ethicist is interested in goodness of character (Gottlieb, p. 1). There is a long tradition of valuing virtue including ancient Greek, medieval Christian and contemporary virtue ethics. While all these traditions are valuable, I focus mainly on Aristotle. There is so much written about and on Aristotle, it would be easy to get lost in a forest of words, thousands of years in the making.

According to Aristotle, virtue is a state of character. To be virtuous is to hit the mean between two extremes. For instance, to be brave is to hit the virtue of courage, missing the vices of cowardice and rashness which lie to either side of courage: "according to Aristotle, each virtue is in a mean between two vices, one of excess and one of deficiency" (Gottlieb, p. 22). Exactly what the mean of courage or any other virtue will be depends on you and your situation.

Excellence, then, is a state concerned with choice, lying in a mean relative to us, this being determined by reason and in the way in which the man of practical wisdom would determine it. Now it is a mean between two vices, that which depends on excess and that which depends on defect; and again it is a mean because they respectively fall short of or exceed what is right in both passions and actions, while excellence both finds and chooses that which is intermediate. ( $N E$ 1107a1-6)

As Gottlieb puts it, "According to Aristotle, since the good human being, with her dispositions in equilibrium, will feel and act in the right way, at the right time, and so on, the correct thing to do will vary according to circumstances" (Gottlieb, p. 25).

To be virtuous, as we have seen in my discussion of flourishing, you need moderate prosperity and good role models; with these in place (especially as you grow up) you can 
develop a virtuous character in large part by learning to feel the right way at the right time.

For instance, both fear and confidence and appetite and anger and pity and in general pleasure and pain may be felt both too much and too little, and in both cases not well; but to feel them at the right times, with reference to the right objects, towards the right people, with the right aim, and in the right way, is what is both intermediate and best, and this is characteristic of excellence" (NE 1106a16-24).

But not every midpoint is a virtuous mean; there is no "right way" to commit murder, or adultery:

But not every action nor every passion admits of a mean; for some have names that already imply badness, e.g. spite, shamelessness, envy, in the case of actions adultery, theft, murder; for all of these and suchlike things imply by their names that they are themselves bad, and not the excesses or deficiencies of them. It is not possible, then, ever to be right with regard to them; one must always be wrong. (NE 1107a9-17)

\section{Aristotle's Mean: Why it is Golden, for Disabled People and Others}

A little to my surprise, Aristotle's doctrine of the mean has a bad rap amongst some philosophers, but both Gottlieb and I find it interesting and useful. In her introduction, she notes: "Aristotle's doctrine of the mean has had a bad press, from being dubbed the 'Goldilocks Theory of Ethics', to receiving Bernard Williams's intended epitaph that the doctrine is "better forgotten"' (Gottlieb, p. 19). Gottlieb begins her first chapter of the mean with, "My point of departure is Aristotle's much-maligned doctrine of the mean. Immanuel Kant thought that it was false and Bertrand Russell dismissed it as 'true, but uninteresting'. I argue that, when properly understood, it is both interesting and true" (Gottlieb, p. 3). In fact, Russell rejected the golden mean as a young man but later came to admire it. “...it may be an uninteresting doctrine, but in a very great many matters it is a true one" (Russell, 1930/1996, p. 178).

Gottlieb suggests Aristotle's mean is often dismissed wrongly when it is confused for a 
decision-making procedure along the lines of Kant's categorical imperative or a hedonistic calculus (i.e. the utilitarian decision-making procedure of weighing up potential action to see if it would cause more or less happiness). The golden mean is not a decision-making process that is analogous to either of these moral theories: both the categorical imperative and hedonistic calculus can be understood as tools which an agent brings to challenging moral dilemmas like a hammer to a nail. But this is not how Aristotle's doctrine of the mean works at all. Instead, the mean is both a description of and a guide towards virtue. Getting frustrated that the doctrine of the mean will not tell you what to do in a challenging situation in the same way that the categorical imperative may, is a little like getting annoyed at your flute for being a terrible can opener. Gottlieb sums up this tension:

It might be thought that if the doctrine of the mean is indeed a doctrine of equilibrium and not a doctrine of moderation, then it has the fatal flaw of being unable to provide a decision procedure for action, a necessity for real life. This criticism is lurking behind complaints that the doctrine of the mean is unhelpful, or true but uninteresting. Taken one way, the criticism misses Aristotle's point. The correct thing to do, according to the second aspect of the doctrine of the mean, is not a 'mean in the object', not something that can be worked out using a mathematical algorithm in some mechanical fashion. So if this is what the detractors are asking for, Aristotle is saying that it cannot be had. (Gottlieb, p. 3637)

Gottlieb argues that in Aristotelian virtue ethics, right action is determined not in the moment by reference to an intellectual tool, but by developing a virtuous character which allows you to behave virtuously in even morally fraught situations. She suggests, and I agree, that the doctrine of the mean is best understood as being about the virtuous person's equilibrium of character, not moderation. For her, equilibrium better captures Aristotle's insight that virtue is a mean, than the singular virtue moderation. Gottlieb argues that Aristotle's doctrine of the mean should be understood as relative to a 
particular virtuous person and their situation, not relative to the virtuous person in the abstract. This is what Gottlieb means by the "second aspect" of the mean. The mean is not the mathematical point between extremes, but the midpoint relative to you.

Additionally, Gottlieb argues that we should read Aristotle as saying all virtues are relative to the individual, not just virtues particularly dependent on circumstance, such as "liberality" (sometimes translated as "generosity"), which may be considered especially agent-relative because in order to be generous, one does need to have something to give. I agree with Gottlieb: individuals' abilities matter, no matter the virtue in question. Her convincing example is that if someone is drowning, a courageous rescue will look different if you are a strong versus a weak swimmer.

I wish to suggest that it does make sense to pay attention to one's own abilities when the other virtues are in play as well. To take just one example, if Henry is a good swimmer, he will be acting bravely if he dives in to rescue a fellow soldier in the heat of battle. If he does not know how to swim, diving in will be rash. In this respect, then, the mean is relative to individual agents and not just to us as human beings. Good people will have to know their own particular abilities, since virtue is relative to them. (Gottlieb, p. 30)

In my opinion, one of the most valuable aspects of Aristotelian virtue ethics for work like mine, aiming to end discrimination on the basis of disability, is that virtue (and therefore right action) is both relative to the individual and absolute in that there will be a precise mid point or mean of virtue for each individual. I agree with Gottlieb, that your abilities are relevant to the mean of virtue for you, but I would add, where Aristotle and Gottlieb do not, that one's impairments are also relevant. As I will argue in more detail in the next chapters, disability and impairment are relevant both to the virtuous disabled person's individual virtue, as well as the collective virtue of groups, institutions and societies. In my view, this means that first, people with disabilities must gain a system of ethics flexible enough to 
include them, but definite enough to allow disabled people to call out injustices perpetrated against them. Aristotle might not share this perspective; this is my own extrapolation from his views and from Gottlieb's interpretation of Aristotle.

I do not wish to suggest that there is a special and different type of virtue for disabled people, not at all. Rather on my definition of virtue drawn from Aristotle, disability (like being able or unable to swim in Gottlieb's example) should be just one of many individual specific factors which go into determining what the mean of virtue is for any virtuous individual. It is only when disability is conceived and perceived as a fixed feature of an individual and is thus taken to make it impossible for disabled people to flourish, or to be virtuous that there is a problem.

Variation and specificity is built into virtue ethics. Unlike Kantian or Utilitarian moral theory, it is both flexible and pragmatic and focused on living well and learning to make virtuous actions. As noted in Section 1, flexibility and pragmatism is part of disability culture and a practical necessity for many disabled people. For Aristotle, right action can and should look different for different people in different situations. What you ought morally to do depends on who you are and what situation you are in. Yet Aristotle is not a relativist. There will always be a virtuous action to take, always a right thing to do; the trick is to be well educated and virtuous enough to discern what this action will be. There are many ways to fail and only one way to succeed:

It is possible to fail in many ways (for evil belongs to the class of the unlimited, as the Pythagoreans conjectured, and good to that of the limited), while to succeed is possible only in one way (for which reason one is easy and the other difficult - to miss the mark easy, to hit it difficult). (NE 1106b29-32)

For Aristotle, virtue (especially moral virtue) is best when it is active. One learns to be virtuous by practicing virtuous acts, and one cannot become good through theory alone: 
It is well said, then, that it is by doing just acts that the just man is produced, and by doing temperate acts the temperate man; without doing these no one would have even a prospect of becoming good. But most people do not do these, but take refuge in theory and think they are being philosophers and will become good in this way, behaving somewhat like patients who listen attentively to their doctors, but do none of the things they are ordered to do. As the latter will not be made well in body by such a course of treatment, the former will not be made well in soul by such a course of philosophy. (NE 1105b13-16)

\section{A Couple Caveats: Where my Definition of Virtue Differs from Aristotle's}

Although I agree with Aristotle for the most part that virtue is a mean between extremes and one achieves it through practice and learning by example, there are a few points on which I differ from Aristotle. First, Aristotle considers a virtuous flourishing life to be both the good life and human beings' ultimate purpose. I agree that virtue and flourishing are part of the good life for people, but I'm not sure we can know whether human beings have an ultimate purpose. This question is close to a religious one and is, therefore, best left to theologians. Moreover, linking together virtue, flourishing and humanity, as Aristotle does, may imply that vicious people or people unable to flourish are less human than people who are virtuous. This is an implication I do not support. Also, for Aristotle, virtue and intellect go hand-in-hand; I think Aristotle put too much emphasis on intellectual ability as I do not think that to be virtuous, one needs any specific level of mental ability. Although Aristotle might disagree, there is also no specific right way to feel pleasure; this is again because, according to Aristotle, virtue is relative to us. Therefore, it might make sense that the correct virtuous emotional state will be different for someone who is, say, autistic and for someone who is neurotypical. People with and without disabilities may get different amounts of pleasure out of different virtuous acts: as long as they are within the mean of virtue, this should not matter. 
Additionally, unlike Aristotle, my goal in defining virtue here is not to settle the question, What is virtue? Or, how can we know if our actions are ever right? Instead, my aim is to use Aristotelian virtue ethics as a starting place to argue that virtue ethics implies a necessity for an accessible world and requires that disabled people must not be blocked from flourishing. There is a hands-on immediacy to Aristotelian virtue ethics which I think makes it especially useful in this context and valuable to disabled people and allies. In this, I follow Aristotle when he writes:

Since, then, the present inquiry does not aim at theoretical knowledge like the others (for we are inquiring not in order to know what excellence is, but in order to become good, since otherwise our inquiry would have been of no use), we must examine the nature of actions, namely how we ought to do them; for these determine also the nature of the states that are produced, as we have said. ( $N E$ 1104a28-32)

Like Aristotle, I am interested in theoretical questions, but wish to put them on hold here and use, rather than defend, Aristotelian virtue ethics. 


\section{Chapter 2}

There is a rose in Spanish Harlem, A red rose up in Spanish Harlem.

It is a special one, it's never seen the sun, It only comes out when the moon is on the run, And all the stars are gleaming. It's growing in the street right up through the concrete.

- Ben E. King, 1961

Introduction

I divide this chapter into two sections. In Section 1, I will argue that disability friendly virtue ethics demands an accessible society in which all disabled people have a chance to flourish. This, I suggest, is due to virtue ethics' focus on the necessity for both collective and individual flourishing. Aristotle's focus on excellence, while exclusive in its original form, can, with insights from disability theorists, be a system of ethics that values the variations in the human experience and human excellence that disability makes possible. It becomes a disability friendly form of Aristotelian virtue ethics that protects the development of excellence in all its forms. Finally, I will demonstrate that virtue ethics grounds the rights of disabled people to accommodation due to their human potential for excellence and virtue in any of its various forms.

In Section 2, I will discuss virtues that are of particular importance and value to disabled people, particularly when navigating societies rife with systemic discrimination and oppression against people with disabilities. I will discuss virtues which Aristotle and contemporary thinkers might agree on, such as pride and justice. I will also discuss 
virtues emphasized by Aristotle that come up less frequently in modern theory. These are the virtues of courage, liberality, and magnificence.

\section{Section 1: Disability friendly virtue ethics}

What is the point of ethics? Is it a tool to help us to ration out precious resources such as pleasure or happiness or satisfaction, as a consequentialist would suggest? Or, an intellectual restraint on our worst impulses, thus holding us back from mutual destruction, as Hobbesians might have us believe? Many people of faith understand ethics as a set of divinely mandated rules. Some followers of Immanuel Kant understand ethics as an unbreakable intellectual law. I think while all these answers have merit to them, they all leave something out: the particularity of each individual that is central to Aristotle's account of virtue.

Each of the other answers to what is morally right is focused on prescription or description in general terms with a slightly mechanical, formulaic, flavour. Pull this lever to get these results. The particulars vary, but the formulae do not. By contrast, Aristotle presents virtue, the key to his Ethics, not as a straightforward set of rules or a system of constraint, but as a way that human nature can be expressed, a technique for living well as an individual, and in community with others. For Aristotle, successful virtue is an expression of individual and collective humanity. Aristotelian virtue ethics is about living well in community. Virtue ethics, although flexible, is not relativism. It is possible to say, for instance, that murder is always vicious, and there is no right way to be a tyrant.

In this work, I assume that disability, rather than being a block to the good life, may be an important element in it. Disability is part of living well, not an obstacle to 
overcome in order to live well. I find featuring disabled people amongst contenders for the Aristotelian good life exciting. It is, I suggest, an empowering possibility for both disabled and nondisabled people.

In my view, Aristotle's technique for achieving virtue and living the good life are open to disabled people. For Aristotle, virtue and virtuous actions should proceed from a virtuous character and will shift from person to person and situation to situation. Yes, disability might change where the mean is, relative to you. So do many other features, characteristics and circumstances. Impairment in and of itself is not a block to virtue, or the good life. In fact, I will argue in Section 2 that there are virtues specific to people with disabilities and elements of the good life more easily available to disabled people.

The goal of disability friendly virtue ethics is to allow everyone including disabled people, the chance to flourish, as individuals and as members of society. One thing about Aristotle's ethics I find encouraging for this purpose is that for Aristotle human life is defined by the potential to live well. Eudaimonia, or Aristotle's deep happiness, is not a bonus, or the thrill of immediate pleasures, but the very soul and centre of what it means to be human. I think there is a good case for requiring that all people be allowed to flourish. Because flourishing is deeply important for every human being, I would suggest it is wrong to block anyone from flourishing who has this potential and I would argue that all people do. I would go further and argue Aristotelianinspired virtue ethics requires an accessible world. If what it means to be human is in part or in whole tied to living well, as Aristotle argues, then I suggest it follows that allowing systemic discrimination or oppression to block disabled people from 
flourishing is unethical. I will discuss this point a bit later in the context of Lisa Tessman's account of burdened virtues.

It might be objected that to assume oppression blocks the path to flourishing, which is in turn the purpose of human life, is to suggest that there is a specific human purpose; a proposition that is difficult to defend. Any fixed definition of humanity may be worrying: Who is in? Who is out? And who gets to decide? I would respond that critiquing oppression because it blocks flourishing, a key part of being human, need not imply a fixed definition of humanity. One does not need to know precisely and in every way what it means to flourish as a human being to register that flourishing is being blocked, and humanity is restricted, by oppression, for example. Stop and undo the oppression and the full extent of each individual's humanity may be expressed and become perceivable. Freedom and opportunity allow a fuller expression of individual potential.

I agree with Oscar Wilde's pithy definition of a perfect personality as "one who develops under perfect conditions, who is not wounded, maimed, or in danger" (Wilde, p. 269). It might further be objected that using disability friendly virtue ethics to create an accessible world in which all people gain the freedom to flourish would have too high a cost. I would respond: Yes. An accessible world would require substantial societal change and demand the use of many resources. But it would be worth it. The logistical or monetary challenges of allowing eudaimonia to be a universal possibility do not negate its rightness; some costs are worth paying. Morality is about what is just or right and not about how much it will cost. Moreover, to suggest that an accessible world 
would be far too expensive implies that an inaccessible world, in which disabled people cannot flourish, has no cost to non-disabled people or society.

My second response to the charge that accessibility is too expensive would be to point out the considerable cost of inaccessibility to both disabled and nondisabled people. An inaccessible world is not inevitable; what disabled people need to flourish is not being allowed to them. This is a problem for disabled people, of course, but also for nondisabled people who are denied the benefits of living alongside flourishing disabled people. Writing in 2009, Michael Oliver sums up the global reality of sharply restricted chances to flourish for disabled people. After drawing his reader's attention to disproportionately high poverty and mortality rates the world over amongst disabled people, Oliver focuses in on the situation in his native Britain and other "developed nations":

Thus, for example, more than 60 per cent of disabled people in both Britain and America currently live below the poverty line. Labour markets in the developed world continue to discriminate to the point where disabled people are three times more likely to be unemployed than their able-bodied counterparts. In education, the majority of disabled children are still educated in segregated special schools and less than three in a thousand disabled students end up in higher education. (Oliver, p. 100)

\section{What We're Up Against: Blocks to Flourishing as Disabled People}

For many disabled people, flourishing is, at present, not a live option. Oliver remarks: "More importantly, at the present time most disabled people in the world live in abject poverty, and do not have enough food and drink, while the two main causes of impairment internationally are war and poverty" (Oliver, p. 49). His point is that there is a certain urgency to disability advocacy. I would argue that blocks to flourishing are unacceptable if one takes on board Aristotle's assumption that to flourish is to express 
one's humanity. Worrying about costs is to fiddle while Rome burns. Again, I would suggest that denying disabled people the chance to flourish is to stunt their humanity, and therefore is morally wrong. It is vicious, in the Aristotelian sense of the word.

The 2011 World Report on Disability, compiled by the World Health Organization and World Bank, soberly notes that in the "developed world," "persons with disabilities, experience worse educational and labour market outcomes and are more likely to be poor than persons without disabilities" (World Health Organization, p. 39; hereafter cited as WHO) and states that acquiring a disability, at the present time, can lead to severe disadvantage. "The onset of disability may lead to the worsening of social and economic well-being and poverty through a multitude of channels including the adverse impact on education, employment, earnings, and increased expenditures related to disability" (WHO, p. 10). The present situation is particularly troublesome for children: "Children with disabilities are less likely to attend school, thus experiencing limited opportunities for human capital formation and facing reduced employment opportunities and decreased productivity in adulthood" (WHO, p. 65-67).

From an Aristotelian virtue perspective, it is particularly worrying that many disabled children do not have the chance to pursue learning. They're missing out both on a fundamental human pleasure, and on learning to be virtuous. Aristotle is clear that in order to be virtuous, education is essential. Children need the chance to learn to love doing what is right by following the good example of teachers who understand the virtues: "It makes no small difference, then, whether we form habits of one kind or of another from our very youth; it makes a very great difference, or rather all the difference" (NE 1103b24-25). For Aristotle, enjoyment of learning, at even the most 
basic level, is the greatest and most common of human joys. These words open his Metaphysics:

All men by nature desire to know. An indication of this is the delight we take in our senses; for even apart from their usefulness they are loved for themselves; and above all others the sense of sight. For not only with a view to action, but even when we are not going to do anything, we prefer sight to almost everything else. The reason is that this, most of all the senses, makes us know and brings to light many differences between things. (Metaphysics 980a25)

Although Aristotle often valorizes the human intellect, the opening lines of the Metaphysics show how joy of learning is fundamental to his understanding of human nature. On Aristotle's account, as long as you are capable of taking in information through one or more senses, you can enjoy learning.

For Aristotle, one cannot be happy under adverse or traumatic conditions, not really. If you think you can, you are kidding yourself: "Those who say that the victim on the rack or the man who falls into great misfortunes is happy if he is good are, whether they mean to or not, talking nonsense" ( $N E$ 1153b20). For Aristotle, the best kind of human happiness is to take pleasure in leading a good life. Pleasure is an intrinsic part of living well and completes each virtuous activity: "for no activity is complete when it is impeded, and happiness is a complete thing; this is why the happy man needs the goods of the body and external goods, i.e. those of fortune, viz. in order that he may not be impeded in these ways" (NE 1153b17-18). Happiness is the crowning glory of a good life and is therefore thoroughly incompatible with, misfortune, torture or, I would suggest, oppression commonly encountered by disabled people such as social exclusion, inadequate health care, institutionalization, or barriers to education and paid work.

According to Aristotle it is not possible to flourish without the basics one needs to live a good life. He notes that a little bit of good or bad fortune does not affect one's 
prospects for true happiness. Serious misfortune or remarkable good luck do have an impact. (NE 1100b25-30). According to Aristotle good luck makes it easier to flourish and gives you the opportunity to handle your good fortune with grace, whereas truly terrible luck can make it impossible to flourish:

Now, many events happen by chance and events differ in importance, for example, small pieces of good fortune or of its opposite would clearly not tip the weigh scales of life one way or the other. But a multitude of great events (if they turn out well) will make life more blessed, for not only are they themselves such as to add beauty to life, but the way a man deals with them may be noble and good, while if they turn out ill they crush and maim blessedness; for they both bring pain with them and hinder many activities. (NE 1100b22-30)

In my experience, half conscious resistance to even the possibility of disabled people actually flourishing is not uncommon. Friends and colleagues often struggle to understand that a disabled life could be a good life. Given that disabled people in twenty-first century Canada and in recent Western history have often been denied the opportunity to flourish, it is not a surprise that some nondisabled people have trouble imagining disabled people living well, especially if they have not yet had the chance to meet and interact with vibrant, flourishing disabled people.

Additionally, political philosopher and racial theorist Charles Mills points out, in his influential book The Racial Contract, that political systems of oppression can become invisible to the very people operating them. The fact that disability is almost always constructed as a disadvantage obscures the fact that disability is not intrinsically negative and need not be a disadvantage.

Ironically, the most important political system of recent global history- the system of domination by which white people have historically ruled over and, in certain important ways, continue to rule over nonwhite people - is not seen as a political system at all. It is just taken for granted; it is the background against which other systems, which we identify as political, are highlighted. (Mills 1997, p. 1-2) 
Of course, it is worse to be dominated than to be unable to perceive domination occurring, but I would suggest neither are conducive to flourishing.

\section{Expanding on Aristotle: The Vices of Oppression}

As I have noted, Aristotle holds the common-sense view that one cannot be happy and flourishing in the midst of disaster (i.e. $N E 1100 \mathrm{a} 8$ and 1100b28). However, for Aristotle, getting what you need to flourish is construed more as a matter of luck than a question of the presence or absence of systemic oppression or discrimination. In his view, luck is crucial: "Since many changes occur in life, and all manner of chances, and the most prosperous may fall into great misfortunes in old age, as is told of Priam in the Trojan Cycle; and one who has experienced such chances and has ended wretchedly no one calls happy" (NE 1100a7-9).

In Burdened Virtues, Lisa Tessman suggests that Aristotle's understanding of external blocks to flourishing should be expanded beyond the vagaries of fortune to include blocks to flourishing often generated by oppression:

Having an analysis of oppression as a structural phenomenon requires seeing social or systemic forces as responsible for the fact that members of some social groups are deprived of these external resources. Hence it requires expanding Aristotle's list of the things that typically interfere with flourishing to include those things that regularly, and in a patterned way, arise as barriers to flourishing under conditions of oppression. (Tessman 2005, p. 35)

Aristotle did not explicitly point out the wrongness of blocks to flourishing generated by oppression, but we can do so. I agree with Tessman's suggestion that it would be helpful to expand Aristotle's account of what it means to be restricted from flourishing, from being a matter of luck to also being a matter of systemic discrimination and oppression. 
The oppression that stops many disabled people from living well is not morally right — even within the framework of Aristotelian virtue ethics. If Aristotle is correct and the purpose of human life is at least in part to live well and virtuously, I would argue it follows that it is wrong to block the potential for flourishing or living well, as is the case when the chance to live well is denied due to oppression, including discrimination on the basis of disability.

The 2006 UN Convention on the Rights of Persons with Disabilities declares the wrongness of blocking disabled people from living well:

The purpose of the present Convention is to promote, protect and ensure the full and equal enjoyment of all human rights and fundamental freedoms by all persons with disabilities, and to promote respect for their inherent dignity. (UN Convention Rights Disabilities, Article 1)

I agree that disabled people are as entitled to live well as anyone is, and that the chance to do so must be protected. To block disabled people from flourishing through political and social structures of oppression and discrimination is wrong.

\section{Section 2: Seven Disability Friendly Virtues}

In this section I will discuss seven specific virtues. All but the last are Aristotelian. Each virtue is, I think, disability friendly, in that, when understood broadly and with reference to other scholars, each of these virtues encourages all people, including disabled people, to live well.

\section{Liberality}

Liberality may seem an odd place to start as it has a slightly obscure ring, but Aristotle's liberality is a financial virtue and as such I believe has more disability friendly implications than might be expected. Aristotle's liberality is the precise 
midpoint between stinginess and extravagance in terms of money or resources. Here, meanness describes stingy, ungenerous behaviour rather than unkindness:

Prodigality and meanness are excesses and defects with regard to wealth; and meanness we always impute to those who care more than they ought for wealth, but we sometimes apply the word 'prodigality' in a complex sense; for we call those men prodigals who are incontinent and spend money on self-indulgence. (NE 1119b27-32)

Here incontinent means moral incontinence or the failure to achieve virtue despite one's awareness of what the proper virtuous action is for you.

The liberal person gives within their means, but as generously as possible, and with a glad heart. "Nor is he liberal who gives with pain; for he would prefer the wealth to the noble act, and this is not characteristic of a liberal man" (NE 1120b30). To be liberal one does not need to be wealthy:

The term liberality is used relatively to a man's substance; for liberality resides not in the multitude of the gifts but in the state of the giver, and this is relative to the giver's substance. There is therefore nothing to prevent the man who gives less from being the more liberal man, if he has less to give. (NE 1120b6-9)

What it means to be liberal shifts with income: more money does not imply more liberality. However, one does need to be at least moderately well off to be liberal.

There are two direct ways I think liberality is an especially disability friendly virtue. First, liberality has the generosity of charity without charity's condescending bite. "As cold as charity" is an old expression, but no one would say, "as cold as financial generosity." The connection between disability and charity is troubled and longstanding. Eli Clare sums up the difficulty in his insightful work Brilliant Imperfection: "Charity has long organized itself around the twin notions that disability is tragic and disabled people pitiful” (Clare 2017, p. 8). 
Of course, the impulse behind charity is often laudable. The problem is that the sympathetic impulse to charity can slide into pity very easily. From a charitable perspective, disability is typically seen as misfortune, and the disabled as waifs in need of rescue. Disabled people then become not equal members of society entitled by rights to what they need to flourish but are objects of pity and charity. Pity and condescension negate the virtue of liberality, as these are the wrong motivations for this virtue; the liberal person uses their money tactfully and respectfully. An attempt at liberality which left the recipient feeling pitied, condescended to, or looked down on, would be a failure of liberality.

It's also important to note that Aristotle's virtue of liberality is very different from the charity that we see today, engaged in large scale international humanitarian work, for example, by Doctors Without Borders, UNICEF, or smaller scale community service organizations like the United Way or local food bank. In contrast to much charity, this Aristotelian virtue cannot function on a scarcity model. The virtue of liberality is not about helping the destitute by providing a minimally decent relief from abject poverty. Rather, liberality is about finding the most fitting and gracious way to be generous with money. The golden mean of the virtue of liberality can only exist in a context of at least moderate prosperity. To exercise this virtue the liberal person must be able to take for granted that fellow citizens are not starving in the streets. In cases of famine or mass societal breakdown where people are indeed starving in the streets, virtues different from liberality would be called for. In such extreme cases the financial virtue of liberality would be impossible to achieve and possibly irrelevant. 
Valuing liberality to the extent of allowing all people to develop their ability to live well would imply that everyone, disabled or otherwise, must have enough money to be able to be generous. If, for a moment, we treat accessibility as an example of the virtue of liberality in action, two things become clear. First, we can observe that condescending or grudging efforts at accessibility will not do; motivation (and emotional states more generally) matter in virtue ethics. Disability friendly virtue ethics must come from a genuine, gracious desire to make things open to everyone. Second, because of virtue ethics' characteristic flexibility, accessibility can vary with individuals, resources, and situations. Still, crucially, as with Aristotle's liberality, some resources will be required for accessibility.

\section{Magnificence}

Like liberality, magnificence is concerned with spending money generously. Aristotle says, "It surpasses liberality in scale" (NE 1122a22). The virtue of magnificence will always require enormous financial resources. It is a public virtue on a grand scale, concerned with vast expenditures, those grand gestures that make a positive impact on the community or collective. For Aristotle magnificence comes especially in terms of aesthetics, public pleasure, prestige, military might, or religious devotion ( $N E$ 1123a19-23). Like all of Aristotle's virtues, it is a golden mean: its excess is tasteless or ostentatious overspending, its deficiency could be called large-scale cheapness. Only individuals or organizations with significant resources can be magnificent:

The man who in small or middling things spends according to the merits of the case is not called magnificent (e.g. the man who can say 'many a gift I gave the wanderer'), but only the man who does so in great things. For the magnificent man is liberal, but the liberal man is not necessarily magnificent. (NE 1122a27-28) 
Aristotle's magnificence might not seem a natural candidate for disability friendly virtue ethics. Yet the cost of transforming a society into an accessible society would be on a scale similar to the creation of universal health care or a universal public school system. The financial outlay would be enormous. Still, the virtue of magnificence would allow for such a transformation. When it comes to doling out resources needed by disabled people, governments and powerful institutions tend to be close fisted, rather than magnificent. A gatekeeping mentality is common; gratitude for scant resources is often expected from disabled people. To my mind there is something wonderfully open handed about Aristotle's magnificence as a virtue.

Some examples of modern magnificence practiced by an individual might include the libraries and concert halls built in cities and towns across North America by Andrew Carnegie in the early $20^{\text {th }}$ Century. Magnificence in the public sphere can also include publicly funded schools and universities or splendid national parks. If governments and institutions within society operated with magnificence, there would be transformative disability friendly results. Universal design would be adopted for all grand projects, services and architecture. Universal design is the design and composition of an environment so that it can be accessed, understood and used to the greatest extent possible by all people regardless of their age, size, ability or disability.

"Universal design is a strategy that aims to make the design and composition of different environments and products useable for everyone. ... The purpose of UD, like assistive technology, is essentially the same: to reduce the physical and attitudinal barriers between people with and without disabilities" (Null 2014, p. 5).

As it stands, even when institutions and governments profess devotion to ideals such as universal design, and commitment to the social model of disability, there 
remains a tendency for handwringing about the cost of accommodation for disability.

Magnificence is destroyed by any stinginess; the magnificent person or, magnificent

group of people, does not care for the cost but is interested in the results:

The magnificent man is like an artist; for he can see what is fitting and spend large sums tastefully. For, as we said at the beginning, a state is determined by its activities and by its objects. Now the expenses of the magnificent man are large and fitting. Such, therefore, are also his results; for thus there will be a great expenditure and one that is fitting to its result. Therefore the result should be worthy of the expense, and the expense should be worthy of the result, or should even exceed it. And the magnificent man will spend such sums for the sake of the noble; for this is common to the excellences. And further he will do so gladly and lavishly; for nice calculation is a niggardly thing. (NE 1122a34-b8)

If governments and large-scale institutions work to guarantee disabled people what they need to flourish in a spirit of magnificence, this would mean guaranteed accommodations for disability, taking it from a grudging act of charity to a willingly embraced opportunity for public grandeur. People and institutions could be proud of their accessible places in the same way we may be now proud of our public parks, monuments and services.

\section{Courage}

Aristotelian courage sits between rashness and cowardice. Aristotle considers it normal to feel fear but believes that virtuous people will feel it in the right way and be willing to act bravely despite personal risk, for the sake of what is right and noble (NE 1115a6-1117b20). Courage is a classic Aristotelian virtue, yet I hesitate to include courage as a disability friendly virtue for two reasons. First, courage is frequently misattributed to disabled people in a way often experienced as condescending. (A great way to annoy someone with a disability is to come up to them as they do something 
ordinary, like getting on the bus, and say: "You are so brave!") Clare, in Brilliant Imperfection, sums up this kind of cringe-inducing encounter, all too familiar to disabled people. "Strangers pat me on the head. They whisper platitudes in my ear, clichés about courage and inspiration. They enthuse about how remarkable I am. They declare me special" (Clare, p. 6). There is arguably a certain courage inherent in living any life, yet, as Clare emphasizes, there is nothing particularly brave about simply living life as a disabled person. This line of thinking assumes disability must be something awful to be faced with courage and overcome every day. This 'overcoming' narrative is prevalent. As Clare says: "Overcoming bombards disabled people. It's everywhere" (Clare, p. 8). There is something faintly hostile about the persistence with which courage is thrust upon disabled people. There must be something really wrong with you if it is so very brave to face everyday life. Simmering just beneath the surface of the platitudes is an irritable demand that we overcome our disabilities completely and "just be normal."

On reflection, however, neither the fact that courage is often misattributed to disabled people, nor the fact that the demand for courage may become a wearing micro-aggression against disabled people, ought to imply that courage cannot be a disability friendly virtue. There is nothing wrong with courage itself. Aristotle's courage is in my view, robust and uplifting. For him, the paradigm example for courage is courage in the face of death, especially death in battle (NE 115a30): "Now the brave man is as dauntless as man may be. Therefore, while he will fear even the things that are not beyond human strength, he will fear them as he ought and as reason directs" (NE 1115b11-12). In my view, Aristotle's understanding of courage can be extended to include courage in many situations. 
Being falsely labelled as brave when you are just living your life is no reason to give up on courage altogether; courage can still be a valuable virtue to disabled people and is often needed to stand up for one's rights. Given that the world is not yet accessible, disabled people often need courage to navigate the built environment and/or advocate for their rights.

However, this leads me to my second worry about courage: its price. I am particularly interested in virtues which advance the flourishing of disabled people; courage is a virtue which is personally risky. Although courage is admirable, it may not always help the courageous person to flourish. Additionally, if courage insofar as it is disability specific is required of disabled people so that they can advocate for what they need, courage does not appear to be a particularly disability friendly virtue. In my view, disabled people should not need to be brave in order to get what they need. I think disabled people should have what they need to flourish. Courage is a virtue that can both help individuals with disabilities and advance collective advocacy for disabled people.

In Burdened Virtues, Lisa Tessman addresses a similar conundrum, noting that the virtues required of oppressed people in the midst of the struggle for liberation can be personally damaging. She suggests that these can remain as Aristotelian-type virtues, despite the damage they do to those who achieve them, since they do broadly aim at flourishing. What Tessman calls "burdened virtues" aim at the creation of a world free of oppression in which everyone can flourish:

Normally, Aristotelian virtues are not (self)-sacrificial: quite the opposite, they are sources of well-being for their bearer. An Aristotelian need not disqualify the traits of the politically resistant self from being virtues, however. Instead, it is possible to conceive of them as 'burdened virtues' associated with resistance, namely, traits that while practically necessitated for surviving oppression or morally necessitated for opposing it, are also costly to the selves who bear them. Their claim to being 
virtues at all derives from their value as means to the envisioned goal of liberation (assuming - well beyond anything in Aristotle's own schema - that this is a 'noble' end. (Tessman, p. 107)

I agree with Tessman's explanation of burdened virtues and would suggest courage (even if it is a burdened virtue) can remain a disability friendly virtue. Given that we do not yet live in a world that is fully accessible, the courage required to help make it so may be a genuine virtue, despite the damage such courage can do to individuals. Additionally, on an Aristotelian understanding of courage, it is not possible to be too courageous. This would be rashness, or recklessness. Courage with an excessive cost to the individual, may not be courage, but a failure of courage. The conditions under which courage requires sacrifice must be carefully judged. Lastly, courage is an invaluable asset to the allies of disabled people who are supporting systemic change to create the most accessible world possible.

\section{Justice}

I suggest Aristotelian justice can help to reframe accessibility as an issue of justice and support the creation and maintenance of laws that encourage the flourishing of all - including disabled people. For Aristotle, justice is a virtue in two senses, one general, one particular. As lawfulness, or general justice, it encapsulates all virtue(s): "And therefore justice is often thought to be the greatest of excellences and "neither evening nor morning star' is so wonderful; and proverbially 'in justice is every excellence comprehended" (NE 1129b27-29). This is because the laws promote all particular virtues such as courage, moderation, mildness, etc. The lawful citizen will therefore possess "complete virtue" (NE 1129b20-27). For Aristotle, it is always just to 
obey the law ( $N E 1129 \mathrm{~b} 12)$, but he is not a strict positivist, i.e one who believes that the law is always and only defined by the letter of the law. He notes that not all laws are equal. The goodness of the law can be judged by how effectively it encourages flourishing.

And the law bids us do both the acts of a brave man (e.g. not to desert our post or take to flight or throw away our arms), and those of a temperate man (e.g. not to commit adultery or outrage), and those of a good-tempered man (e.g. not to strike another or speak evil), and similarly with regard to the other excellences and forms of wickedness, commanding some acts and forbidding others; and the rightly-framed law does this rightly, and the hastily conceived one less well. ( $N E$ 1130a)

Aristotle suggests good laws effectively encourage the flourishing and happiness of all persons the law creators consider relevant: "Now the laws in their enactments on all subjects aim at the common advantage either of all or of the best or of those who hold power, or something of the sort; so that in one sense those acts are just that tend to produce and preserve happiness" (NE 1129b15-17). Aristotle suggests good laws do this effectively and bad ones less so.

If, as Aristotle suggests, good laws can be judged by how effectively they encourage and protect flourishing amongst everyone governed by the laws in question, then I argue that the flourishing of disabled people must be taken into account if laws are to be considered just. An important addition to Aristotle's position, from a disability perspective, is to clarify that disabled people ought to be considered citizens, protected by the laws of society.

An Aristotelian-inspired definition of justice has the advantage of making it clear why injustice damages everyone. On an Aristotelian view, one cannot live well and be unjust, not really. You might be able to be superficially happy, but you will never 
flourish fully, never live as well as you might (NE 1138a29-b5). Injustice is a vice damaging the unjust, corrupting character and blocking the path to flourishing. Injustice harms those affected by it, but also those who are themselves unjust. Neither can flourish fully. Injustice is bad, not just for the individual but for societies, institutions or organizations.

It may seem a little puzzling to suggest that injustice damages unjust people as well as the victims of the injustice; we may feel that part of the problem is that unjust people are sometimes happy, reveling even, in their injustice. But as Lisa Tessman suggests in Burdened Virtues, many people who appear to be privileged and living the good life suffer from what she calls the 'ordinary vices of domination': "Thus many groups of people thought to be living well clearly exhibit moral vices (such as callousness, greed, self-centeredness, dishonesty, cowardice, in addition to injustice)" (Tessman, p. 55). Tessman sums up the piece of Aristotelian-style thinking that allows for this distinction. She points out that there is a difference between being superficially happy and flourishing in Aristotle's deep sense, going on to note that flourishing is in part a communal or collective activity dependent on a community which allows one to live well.

For it turns out that privileged people can be said to be happy without granting that they flourish. The distinction helps uncover a key assumption of interdependence behind the belief that even the so-called other-regarding virtues (and not just selfregarding virtues) are necessary for one's own flourishing; if people are interdependent in such a way that the flourishing of one is tied to the flourishing of all, then for the privileged to flourish they would have to worry a lot more about the well-being of the disadvantaged. (Tessman, p. 7)

\section{Pride}


Aristotle calls pride the crown of excellences: "Pride, then, seems to be a sort of crown of the excellences; for it makes them greater, and it is not found without them" (NE 1124a). As always, pride is a mean: in this case between vanity and undue modesty. "Now the man is thought to be proud who thinks himself worthy of great things, being worthy of them; for he who does so beyond his deserts is a fool, but no excellent man is foolish or silly" (NE 1123b3-4).

The proud man is not pushy but doesn't hesitate to claim what should be his. For Aristotle, failing to be proud when you should be is a vice: "The man who thinks himself worthy of less than he is really worthy of is unduly humble, whether his deserts be great or moderate, or his deserts be small but his claims yet smaller" (NE 1123b1012). Pride is an important element of many "liberatory struggles", a phrase Tessman uses throughout her book, Burdened Virtues: Virtue Ethics for Liberatory Struggles. Pride can be a driver of social change. Pride is a key part of collective advocacy work for disabled people.

I see four clear advantages of Aristotelian pride as a disability friendly virtue and one serious difficulty. First, the advantages: Aristotelian pride, because it is in part defined by justified self-worth, can give disabled people a useful tool in advocacy work; knowing one's worth and one's dignity as a disabled person can make it easier to demand one's rights (the fierceness of Aristotelian pride would expect nothing less). Second, for Aristotle, pride is an important part of the virtuous person's character and I suggest this includes the virtuous disabled person's character. Because, like all of Aristotle's virtues, pride can and should vary from virtuous person to virtuous person; disabled people can and should take pride in the 
excellences specific to them as disabled people and individuals. Third, Aristotelian pride can prove a useful counterweight to societal pressures faced by disabled people, which implicitly or explicitly suggest that disabled people should not be proud or that they should be proud in what Aristotle would call the wrong way. Aristotelian pride should not include too much gratitude or subservience. This passage from Universal Design may illustrate the point.

Here again, people needing equipment are discounted as not being whole people. We are considered to be "patients." We should be grateful to have an oxygen system that keeps us breathing or a wheelchair that provides mobility. Whether or not the product looks nice, is easy to live with, or is available at a marketable price is unimportant to those developing and providing it, or to those of us who have to use it. (Null 2014, p. 3)

Fourth, and finally, I suggest Aristotle's assertion that the proud person is happier to give than to receive may prove unexpectedly valuable to disability friendly virtue ethics. Aristotle, I think, understands the power dynamics involved in delivering and receiving services; he suggests that giving or bestowing benefits is more in keeping with the proud person's nature than receiving them. Aristotle senses that there can be something demeaning about being placed in the role of recipient. It is a position disabled people are often put in when needed services and accommodations are framed as charitable gifts, and gratitude is demanded. Aristotle might see that this is an affront to the proud person of whom he says, "And he is the sort of man to confer benefits, but he is ashamed of receiving them; for the one is the mark of a superior, the other of an inferior" ( $N E$ 1124b10-12).

There is one difficulty with interpreting Aristotle's pride as a disability friendly virtue. He argues that to achieve the virtue of pride, there must be some greatness to you 
that makes you ready to achieve pride. To illustrate, Aristotle gives a worrying example: "For he who is worthy of little and thinks himself worthy of little is temperate, but not proud; for pride implies greatness, as beauty implies a good-sized body, and little people may be neat and well-proportioned but cannot be beautiful" (NE 1123b5-8). Aristotle's assumption that "little people" cannot be beautiful or, one assumes, great, suggests that anyone whose body is different from Aristotle's beauty norms would not be considered beautiful, or by extension great. Since greatness is a requirement for pride, we must conclude that for Aristotle, any disabled person with a unusual body could not be proud.

Yet, once again, I think Aristotle's own awareness of how vital context is to achieving the mean of virtue may ride to the rescue. Beauty norms shift; indeed, it is a part of the job of disabled activists and allies to see that they do. Aristotle is right in a sense that it is hard to be proud, if beauty standards in one's society tell you that you are not, and could never be, beautiful. Of course, challenging oppressive norms of beauty has also been and continues to be a powerful part of feminist movements. The key, then, is to ensure that ideas of beauty like Aristotle's do not rule, and that the beauty Aristotle assumes to be part of greatness is acknowledged to take many forms.

\section{Humour}

For Aristotle, humour is a social virtue. Properly judged, humour is part of good character. According to Aristotle, the virtuous person knows how to be humorous without trying too hard to be funny, being crude, or worrying too much about defending the target of their jokes: 
Those who carry humour to excess are thought to be vulgar buffoons, striving after humour at all costs, and aiming rather at raising a laugh than at saying what is becoming and at avoiding pain to the object of their fun; while those who can neither make a joke themselves nor put up with those who do are thought to be boorish and unpolished. But those who joke in a tasteful way are called readywitted. (NE 1128a5-7)

Humour in disability culture can be a source of fun or a political tool used by advocates to highlight the absurdities of a variety of prejudices against disability. Amongst themselves disabled people, across impairments, have developed a joyous, slightly dark or sardonic wit that is disability culture specific. Humour also effectively smooths communication between disabled and nondisabled people, easing anxieties on both sides. Aristotle's understanding of humour as a virtue may help to explain the weight and value of disability humour. It can be a tool for advocacy and social change.

A wonderful informal example of disability humour as a tool for advocacy is Stella Young's funny and effective TED talk, "I am Not Your Inspiration, Thank You Very Much", in which Young entertainingly debunks the idea that disabled people are inspiring just because they are disabled. "I'm sitting in this chair looking like I do, on the stage and you are probably kind of expecting me to inspire you," (Young, 2010) she says before launching into her critique of 'inspiration porn': a disability-culture nickname for hyper inspirational media images and stories about disabled people. Young gives the example of a poster bearing the image of a male amputee swimmer, and the words: "The only disability in life is a bad attitude." Young's quote here and the nickname 'inspiration porn' give, I think, a good sense of disability humour. It is irreverent, insightful, and a strategy for reducing harmful stereotypes about disability. 
In The Capacity Contract, Stacy Clifford Simplican discusses the role humour can play in disrupting stereotypes surrounding disability and in supporting communication between disabled and nondisabled people:

By integrating humor formally into their agenda, self-advocates and allies disrupt cultural assumptions of intellectual disability as pitiful, repulsive, or childlike. Humor enables nondisabled and disabled people to move through their anxiety, and it is one of the many skills that people with disabilities learn in order to put the other at their ease. (Simplican 2015, p. 126)

Simplican notes that humour is something of a double-edged sword for disabled people. Disability Studies scholars note that humour has a 'double-edged nature' for people with disabilities, "constituting them as laughable spectacles in some circumstances and as empowered agents of humor in others. This difference often hinges on who controls, deploys and sanctions humor in order to create insiders and outsiders" (Simplican, p.?)

Disability humour used in advocacy to smooth lines of communication travels well. However, humour amongst disabled people for disabled people tends to be sharper and darker; it may not travel as well outside of disability culture, as I discovered one afternoon when I first arrived in Ottawa, Canada. I was riding the bus past Parliament Hill with a non- disabled friend. Across from Parliament there stands a reverential statue of Terry Fox, running with his prosthetic leg, looking noble. Ah... this is the perfect time for my Terry Fox joke, I thought, and launched in: "How do you kill a one legged fox? ... Make it run across Canada to cure cancer." To say it landed like a lead balloon would not do justice to the situation. Terry Fox was a beloved hero to my friend. It was a sticky moment.

I do not mean to suggest that my Terry Fox joke is an exemplar of virtuous humour or, I must admit, tact. But I think it illustrates the transgressive sharpness of 
disability humour amongst disabled people. The joke was told to me by my friend Justin, himself an amputee following a workplace accident age twenty; Justin learned the joke from a fellow amputee while recovering from the loss of his leg in rehabilitation, where it appears the "inspirational" presence of Terry Fox loomed large.

Importantly, disability humour amongst disabled people tends not to be selfdeprecating or gentle but pointed, its target often oppressive stereotypes including "inspirational" stereotypes or those who have come to embody them. Terry Fox, to many disabled people, stands in for the "super disabled person": this figure never complains, "doesn't think of themselves as having a disability" and undertakes Herculean tasks even to the death. Although this kind of humour does not always travel, it is a valuable part of disability culture. Across impairments it is part of consciousness raising, bringing oppressive ideas into sharp focus for disabled people, allowing us to recognize them and laugh instead of knuckling under. Although I do think it is worth critiquing the way Terry Fox's legacy is taken up culturally in Canada from a disability perspective, my joke is intended as a example of internal disability humour, not as a critique of Terry Fox himself or his work.

I think Aristotle's insight that humour is a virtue may prove helpful here as it is difficult to defend the virtue of using humour to damage, whereas using it as a tool for positive social change may contribute to the flourishing of everyone and therefore is a virtuous action.

\section{Trust}


Before wrapping up my section on virtues, I would like to add one final disability friendly virtue: trust. Aristotle comes close to elevating trust to a virtue in his discussion of friendship. Aristotle points out that friendship needs trust to be genuine. Aristotle says the best kind of friendship is between people of equal virtue:

Further, such friendship requires time and familiarity; as the proverb says, men cannot know each other till they have 'eaten salt together'; nor can they admit each other to friendship or be friends till each has been found lovable and been trusted by each. Those who quickly show the marks of friendship to each other wish to be friends, but are not friends unless they both are lovable and know the fact; for a wish for friendship may arise quickly, but friendship does not. (NE 1156b25-32)

I think trust is a virtue in its own right and one that is particularly prevalent in disability culture. I suggest this can be seen in two ways. First, disabled people, of necessity, need to place trust in assistants and assistive devices. Everyone needs to trust, but this need and capacity for trust is, I suggest, more immediate and urgent for many disabled people. The urgency of this trust may make the value of trust clearer for disabled people and the mean of trust easier to find. I suggest this mean lies at the midpoint between the vices of excessive suspicion and credulousness.

In her paper "Disavowals of Disability in Rawls' Theory of Justice and his Critics," in Disability and Political Theory, a collection of papers on disability and politics, Simplican discusses the unique way in which trust can expand across the spectrum of impairments. She suggests that most disabled people have the ability to give or withdraw trust and therefore can in some measure participate in the social contract. Moreover, Simplican, drawing on Anita Silvers and Leslie Pickering Francis's paper, "Justice through Trust: Disability and the 'Outlier Problem' in Social Contract Theory," notes that when people with very severe intellectual impairments are included in society fully, nondisabled people may feel safer in that society because they may trust that their 
position in society is not, in any way, contingent or dependent on their own capacity:

"For people's trust in whether a society really understands and is committed to justice is influenced by whether inferior treatment of the disabled and other 'outliers' is prohibited or permitted." (Simplican, 2005, p.74).

While Silvers and Francis dislodge individual capacity as a requirement of social contract theory, they seem to presume that non-disabled people possess a high level of concern for the quality of treatment shown to people with severe disabilities - an assumption again weakened by entrenched prejudice. (Simplican, p.126)

I find Silvers and Francis a little more compelling than Simplican seems to, although I share Simplican's concern about high levels of societal prejudice, especially against those with more severe intellectual impairments. Yet I think Simplican underestimates the value to nondisabled people of trust created by people with disabilities. The presence of such trust can, I would suggest, help to erode the very prejudice that worries Simplican. Silvers and Francis argue that trust is integral to justice. They suggest that rather than being outliers on the edge of trust and justice people with severe disabilities are integral to both. They argue that trust between individuals in society, necessary to a just collective, is built up and continually reinforced by the trust between those with severe impairments and those without.

Justice reigns, we argue, in virtue of having been shaped in response to the need of "outliers" to achieve successful personal trust relationships. From their flourishing comes a climate of general confidence in the comprehensive embrace of justice. Central to cooperative schemes are relationships that do not necessarily produce dyadic exchanges of benefits between pairs of parties but that result importantly in beneficial social by-products that are secured because parties with different levels and kinds of vulnerability successfully cooperate. On this more complex picture, the discretionary commitment to trusting each other by parties whose capabilities differ sustains cooperation not because the parties necessarily reciprocate directly to each other but because their interactions enrich another kind of entity, the cooperative scheme (or the social climate, the community culture, or society itself). Disabled people and other "outliers" can participate actively in such triadic 
relationships. In doing so, disabled people and other "outliers" not only entrust themselves to, but also are trusted by, the rest of the community. Such

relationships can be transformative for all parties. (Silvers and Francis 2005, p. 45)

Although Silvers and Francis are contract theorists and not virtue ethicists, I think they provide a good account of how valuable trust, as a disability specific virtue, can be to both disabled and nondisabled people. Disabled people may have an edge when it comes to achieving the virtue of trust and can demonstrate the virtue of trust in a way that allows nondisabled people to trust more easily. I would argue that a society that fosters trust encourages other virtues, including, as Silvers and Francis suggest, justice. 


\section{Chapter 3}

"Draw the circle wide, draw it wider still"

- Hymn, Gordon Light

\section{$\underline{\text { Introduction }}$}

In this chapter I will focus mainly on including people with intellectual impairments in disability friendly virtue ethics. I will argue that both theoretical and practical societal inclusion of people with intellectual impairments encourages intellectually impaired people, and fair-minded nondisabled people, to live well. I will suggest everyone can flourish and all people have the potential to be virtuous. To the question, "Should we include even this person?" the answer will always be, "Yes." In addition, I will highlight a few problematic instances of exclusive thinking in philosophy.

\section{Section 1: Flourishing with disabilities? You bet!}

Flourishing with Intellectual Impairments

Can people with intellectual impairments flourish? Of course; but you would not know it from the way some philosophers talk. In philosophy, the equal value of intellectually impaired people to nondisabled people is questioned with troubling regularity. Philosophers Peter Singer, R.G. Frey and Martha Nussbaum all doubt that 
intellectual impairments and flourishing are compatible. I will discuss their respective positions later in this chapter.

Why would it seem reasonable to question whether intellectually impaired people can flourish? Can women live well? Without specifying a context this seems a sexist question. It implies that there might be something about women that makes it impossible for them to live well, clearly a sexist idea. In my view, asking if it is possible for intellectually impaired people to flourish is discriminatory in the same way. Because there appears to be so much genuine doubt within philosophy about whether people with intellectual impairments can flourish, I think it is worth addressing this head-on and at some length.

There is a lively contemporary debate surrounding the moral status of people with severe intellectual impairments. Two aspects of this debate are of interest here. First in animal ethics, the well-known argument for marginal cases questions the moral status of intellectually impaired people. The argument from marginal cases involves a negative judgment when comparing flourishing as an intellectually impaired person and flourishing as an animal. Second, some definitions of moral personhood deny the moral agency of people who are severely impaired intellectually.

It is a key feature of my disability friendly ethics that all human beings are persons, and that everyone matters morally. In this chapter I critique three arguments that diminish the value of people with intellectual impairments. Two of the three involve the argument from marginal cases and the third is part of the broader debate about personhood. 
The argument for marginal cases originated in the 1970's with Peter Singer, but has since become a popular argument with many animal rights advocates, it usually runs along these lines:

1. Human beings' moral worth is tied to standard human capacity.

2. Some intellectually impaired people lack capacities which some animals have.

3. We should allow moral status to those animals with more capacities than some people with intellectual impairments.

4. If 1 through 3 are persuasive it is inconsistent to accord higher moral status to intellectually impaired people than to capable animals.

Gerald V. O'Brien, summarizing the argument for marginal cases for a nonphilosopher audience, gives a clear sense of the argument in "People with Cognitive Disabilities: The Argument from Marginal Cases and Social Work Ethics":

Singer (1975) initiated what would later become known as the Argument from Marginal Cases in his book Animal Liberation, often referred to as the "bible" of the animal rights movement. In the book, Singer argued that, if we examine more deeply the basis on which our opposition to discrimination on grounds of race or sex ultimately rests, we will see that we would be on shaky ground if we were to demand equal rights for blacks, women, and other groups of oppressed humans while denying equal consideration to nonhumans. (O’Brien, p. 331)

The argument for marginal cases (AMC for short) was developed to expand the moral community by drawing animals into the circle; an unintended consequence has been to push some disabled people out. O'Brien agrees, stating:

Animal rights scholars who appeal to the AMC appear to be genuinely interested in invoking the argument to enhance the moral standing of the great apes and other 'higher functioning' animals, and largely discount the contention that the argument might have the reversible effect of dehumanizing vulnerable members of the human species. (O’Brien, p. 332)

O'Brien uses the term "animalization" to describe this dehumanizing effect.

Defenders of the argument from marginal cases, I think unconsciously, echo this 
unfortunate line of thought:

Of all marginalized groups, surely those with cognitive impairments are among the most vulnerable to being 'animalized.' The taxonomic status of people with mental disabilities, especially 'feeble-mindedness' or mental retardation, has been a topic of intense debate for centuries. (O'Brien, p. 332)

O'Brien notes that comparisons between animals and disabled people have a long and sordid history. Such comparisons have even been used to promote exterminating disabled people:

In 1901, Duncan McKim, one of the few advocates of eugenic control to openly favor euthanasia of those with severe cognitive disabilities, wrote in favor of painlessly killing these 'beings with less intelligence than the goose, with less decency than the pig.' Feeble-minded people were viewed as animalistic entities because of their purportedly high procreation rates, their inability to live cultured lives, their presumed insensitivity to pain, their propensity for immoral and criminal behavior, and their instinctual rather than rational nature. (O’Brien, p. 125)

This line of thinking eventually produced eugenic policies across the world, most notoriously in Nazi Germany: "In the United States and Nazi Germany, eugenic measures that were taken against people with cognitive disabilities were reinforced by comparing these people to animals, as well as by the wide-ranging use of animalistic metaphors to describe them" (O'Brien, p. 333).

The second strand of the contemporary debate concerns personhood, asking if certain cognitive capacities should be required for a being to be considered human, and some philosophers like Singer say yes. While many in the disability rights movement feel that this is an arbitrary requirement with worrisome consequences, some philosophers similarly feel that a strict requirement for a high level of cognitive capacity is arbitrary, but still think specific cognitive capacities should be required for personhood. I believe Martha Nussbaum falls into this category, since she requires that people have the potential for certain capabilities to 
be fully human (I will discuss her views in more detail shortly). Although these debates are largely theoretical, a theoretical debate on the personhood of all intellectually impaired humans can easily turn into a debate on whether intellectually impaired people should have full citizenship and rights under the law.

For instance, in their paper, "Rethinking Membership and Participation in an Inclusive Democracy: Cognitive Disability, Children, Animals", Sue Donaldson and Will Kymlicka point out that in the past, specific capacities have been required for citizenship. One example is linguistic capacity, but this requirement may sometimes exclude intellectually impaired people from citizenship and has been challenged by intellectually impaired people and allies in struggles for citizenship.

Recent citizenship struggles for people with CD [Cognitive Disability] offer a very different conception of the basis and purpose of citizenship - a conception based not on the possession of linguistic agency, but on rights of membership and participation in a society of equals. Citizenship isn't a select club for linguistic agents; it's a commitment to include and empower all members of society, across the whole spectrum of diversity, on their own terms. (Donaldson and Kymlicka 2016, p. 168)

I do not think a being must have any one specific intellectual capacity or set of intellectual capacities to be human. I do think that a good human life always involves flourishing and virtue; yet I do not suggest that a human being must be either flourishing, or virtuous in one particular way to be a person. The idea that there might be creatures that look like people but aren't quite takes us dangerously close to dehumanizing ideas of monstrosity.

\section{A Brief Discussion of One Example}

One type of intellectual impairment, which in my society ( $21^{\text {st }}$-century Canada) seems particularly stigmatized, is dementia or memory loss in old age. There is a sense 
that living well with dementia is impossible. However, The Fix, a recent (2018) article and documentary film by Moira Welsh and Randy Risling is a good example of how people with dementia can indeed flourish. The film and article follow the transformation of Peel Long Term Care facility, home to elderly residents with dementia, in Ontario Canada, from a chilly institutional place of confinement and task oriented clinical care, to a space in which people with dementia feel at home and enjoy connecting with family, friends and assistants. Dr David Sheard, British dementia care expert, the catalyst for change at Peel initially declared the facility "empty of kindness, laughter or any semblance of hominess" (Welsh and Risling 2018, p. 3).

He was able to initiate a profound shift from the regimented, restrictive, asylumlike environment to a warm and inviting place to live well. Initially:

Residents spent the day "parked" in chairs "like non-people." Staff, when present, talked to each other over the heads of residents, as if they did not exist. The moment to moment experiences of people with dementia living in the care home were, before the changes, grim and isolated: "Every day Inga Cherry sits for hours at the end of a long hallway in a locked dementia unit and stares at the cars speeding along Mississauga's Derry Rd. "I'm in a cage," she says, "In a cage." (Welsh and Risling, p. 1)

The shift was to an environment in which, both staff and residents could flourish.

The new model is a place where "we get love back into care," he says. "We give staff permission to stop being detached. It's a place where people with dementia are busy, in their own ways that we don't always understand, but you know it's linked to something in their past. And to be busy you need a place full of the stuff of life - not an empty building called long-term care.” (Welsh and Risling, p. 4)

After a year of transformation, people with dementia were flourishing.

After dinner, Inga ends up sitting at the puzzle table. Malton Village's administrator, Jessica Altenor, is here tonight spending the evening with her father, Christophe, 85, who has dementia along with Parkinson's disease and lives on Redstone's active side. Christophe can sing in perfect pitch with every Elvis or Tom Jones song ever recorded. Peter, Inga's tablemate, is organizing wooden pieces of a puzzle on the table. We've got a group effort going on here," Jessica 
says. She pulls down a laundry basket and passes it to a lady who just finished folding tea towels. "Would you mind doing a few more?" The lady does not mind. (Welsh and Risling, p. 16)

In this vignette, we can note every element in my definition of flourishing, pleasure, doing the right virtuous thing and accessibility. As people play games, enjoy music and do chores together, the virtues of cooperation, friendship and courtesy are present. The environment is accessible, allowing people with dementia to connect with family, friends and staff; everyone is having fun. Even staff found that the changes made their lives better, "we get to know them and understand who they are. They're not just here in a chair, getting medicine and sleeping" (Welsh and Risling, p. 19). I think this article gives a sense of how dementia or other intellectual impairments can be part of a flourishing good life.

\section{Inclusion: A Gateway to Flourishing, At Least in Theory}

Having severe dementia or a marked cognitive impairment is, in my experience, often seen by philosophers as a worst-case scenario or even as a fate worse than death. I would suggest this is a puzzling perspective if you are intellectually impaired and flourishing or have had the chance to spend time with intellectually impaired people who are flourishing. Such a perspective on intellectual disability may arise from fear. Fear of disability as a perceived weakness is, according to Jay Timothy Dolmage, an embedded characteristic of higher education, the world in which many philosophers move. "Further, the ethic of higher education still encourages students and teachers alike to accentuate ability, valorize perfection, and stigmatize anything that hints at intellectual (or physical) weakness" (Dolmage 2017, p. 3). Perhaps because the life of 
the mind is so important to philosophers, I think an element of discomfort with disability can creep into even supposedly neutral discussions of intellectual impairment.

Some philosophers deny emphatically that disabled people can flourish, arguing that disabled people do not have lives worth living, or do not count morally, because they cannot enjoy life. Peter Singer claims that in some limited circumstances it is morally permissible to kill disabled infants and R.G. Frey argues that it may be right to perform scientific experiments on intellectually impaired people without consent. Even when a philosopher is on the right side, so to speak, they can have worrying views. For instance, Aristotle expert Martha Nussbaum is, to her credit, a vocal supporter of disability rights but also believes some people with dementia may not be persons, in the full moral sense (Nussbaum 1992, p. 26).

So what is going wrong here? In my opinion such views are rooted in each of these philosopher's attitudes (in my view unconsciously discriminatory) towards disabled people. This makes it difficult for them to imagine how people with disabilities can flourish or register the ways in which their own flourishing could be enhanced by the presence of flourishing disabled people. As such views, which I will now discuss more fully, are refuted, and theoretical disciplines like philosophy become more inclusive, better ideas may trickle down and influence practice in ways that make society more inclusive. 


\section{$\underline{\text { So Some Lives are Not Worth Living? }}$}

\section{Singer}

Let's start with Singer as his worrying views on disability are perhaps the best known. He argues it is acceptable to kill disabled infants. His argument runs like this:

1. There is no morally defensible line between a foetus and a newborn infant.

2. It is morally acceptable to abort a foetus; one acceptable reason to abort is that the foetus has a disability.

3. Because there is no defensible moral line between a foetus and a very young infant, it is morally acceptable to kill an infant with a disability.

I pointed out that many societies allow a pregnant woman to kill a foetus at a late stage of pregnancy if there is a significant risk of it being disabled; and since the line between a developed foetus and a newborn infant is not a crucial moral divide, it is difficult to see why it is worse to kill a newborn infant known to be disabled. (Singer 2011, p. 202)

Speaking of infants with spina bifida and intellectual impairments, Singer notes: "In short, the existence of these children caused great difficulty for their families and was often a misery for the children themselves" (Singer, p. 202). Given that Singer is a preference utilitarian, a type of consequentialist who believes it is morally right to maximize ability to satisfy preferences, I can understand his argument here. He is working to minimize suffering, a laudable goal. However, Singer seems very sure he can know when a life is one of suffering and when that life will bring suffering to family members. This certainty is unsettling to me. I would suggest it is based in prejudice. One of his explicit moral justifications for killing disabled infants employs a direct parallel between disabled infants and animals. The comparison denies the humanity of disabled people and degrades them. 
We do not doubt that it is right to shoot badly injured or sick animals if they are in pain and their chances of recovery are negligible. To 'allow nature to take its course', withholding treatment but refusing to kill, would obviously be wrong. It is only our misplaced respect for the doctrine of the sanctity of human life that prevents us from seeing that what it is obviously wrong to do to a horse, it is equally wrong to do to a disabled infant. (Singer, p. 113)

Singer's defense of killing newborns who have profound disabilities is definite. While he sometimes uses softer terms such as "helped to die," (Singer, p.184) more often he uses the words kill, killing or to kill. He includes justifications like parents' loss of happiness and clarifies explicitly that in his view it can be right, in certain circumstances to kill such infants: "Therefore, if killing the hemophiliac infant has no adverse effect on others, it would, according to the total view, be right to kill him" (Singer, p.186).

A disability friendly virtue ethics must categorically reject the notion that human and animal flourishing should be treated as identical. Arguments like Singer's are part of why I find this distinction crucial. Treating horse and human flourishing as the same is category confusion, which I suggest partially motivates Singers' conclusions. Humans and horses have very different realities, from body shape to family life and much more. I do not know what the good horse life is, but it is not the good human life, and this matters. There is a fun house mirror distortion to Singer's argument here. I believe it is a fallacy of composition. Notice that in order to refute him, I have had to clarify that disabled people are different from horses. Comparing a minority group to an animal is a common way of degrading that group, I do not think this is what Singer is aiming at, but it is what he achieves.

Harriet McBryde Johnson captures the tilt-a-whirl feel of Singer's arguments well in her article "Unspeakable Conversations." On her conversation with Singer, she writes: 
He insists he doesn't want to kill me. He simply thinks it would have been better, all things considered, to have given my parents the option of killing the baby I once was, and to let other parents kill similar babies as they come along and thereby avoid the suffering that comes with lives like mine and satisfy the reasonable preferences of parents for a different kind of child. It has nothing to do with me. I should not feel threatened. Whenever I try to wrap my head around his tight string of syllogisms, my brain gets so fried it's ... almost fun. Mercy! It's like "Alice in Wonderland. (McBryde Johnson 2003)

Johnson points out that Singer's view of disabled people, as always and in every way worse off, is based on pernicious negative stereotypes of disabled people. She brings his prejudices to the surface, showing how Singer's arguments, which lead him to endorse (only in theory, but surely that's bad enough) the killing of children, are based in common disability prejudice and not, as Singer thinks, in clearheaded utilitarian calculus. As McBryde-Johnson puts it,

Are we "worse off"? I don't think so. Not in any meaningful sense. There are too many variables. For those of us with congenital conditions, disability shapes all we are. Those disabled later in life adapt. We take constraints that no one would choose and build rich and satisfying lives within them. We enjoy pleasures other people enjoy, and pleasures peculiarly our own. We have something the world needs. Pressing me to admit a negative correlation between disability and happiness, Singer presents a situation: imagine a disabled child on the beach, watching the other children play. It's right out of the telethon. I expected something more sophisticated from a professional thinker. I respond: "As a little girl playing on the beach, I was already aware that some people felt sorry for me, that I wasn't frolicking with the same level of frenzy as other children. This annoyed me, and still does." I take the time to write a detailed description of how I, in fact, had fun playing on the beach, without the need of standing, walking or running. But, really, I've had enough. I suggest to Singer that we have exhausted our topic, and I'll be back in touch when I get around to writing about him. (McBryde-Johnson 2003)

A telethon, which McBryde-Johnson mentions above, is a fund-raising strategy used by many charities throughout most of the 20th century and today. In a telethon, a television or radio station backed by a charity plays nothing but tragic stories of people in need (often, disabled children); the audience is asked to call in and donate. 
It can be very effective in terms of fundraising, but telethons are sharply criticized by disability advocates because they portray disabled people, and especially disabled children, as pathetic and pitiable in a way which is often degrading. The problem with telethons from a disability perspective is summed up in Telethons: Spectacle, Disability, and the Business of Charity by Paul K Longmore:

With rare exceptions, those doing the giving on telethons were nondisabled. People with disabilities were the ones ceremonially defined and displayed as inevitable objects of charity. Telethons offered occasions for individuals to act upon genuinely compassionate regard for their fellow human beings, but this caring was inseparable from the restrictive and depersonalizing social identity imposed on disabled people. (Longmore 2016, p. 59)

In my personal experience, philosophers, especially consequentialists like Singer, can be adamant that there is no insult inherent in likening disabled people to animals. I have had many a debate about such comparisons (and indeed, I have fled from one or two). Building up (understandably in my view) a head of steam on this point, Simplican, in her The Capacity Contract, notes: "Peter Singer is, of course, emblematic of the belief that some nonhuman animals deserve more respect than do the intellectually disabled. His argument is all too familiar, but somehow philosophers and theorists never get tired of hearing it" (Simplican, 2015, p. 69).

Simplican here is referring to the argument for marginal cases (i.e. the argument sometimes raised by consequentialists, including Singer, that, because some animals have equal or greater capacities than some disabled people, some animals deserve more moral consideration than some disabled people). Here, Singer is talking about pain but also capacity. He argues that if you do not have the capacity to live freely from pain and 
your life will include a disability, especially an intellectual disability, you should be killed as a child. Singer names children with Down syndrome (Singer, p. 211- 213).

There's a lot to worry about in Singer's position. With the intention of decreasing suffering, he is advocating for something appalling. In fact, people with the disabilities he names can have good, flourishing lives. Singer is being exclusive in his theory. He has decided people without certain capacities do not merit the same moral treatment as people who have capacities. I believe Singer is being vicious in Aristotle's sense, i.e. a failure of virtue which is bad for an individual or group and society as a whole. (NE 113b15) It is arrogant to assume that you know someone else's life is not worth living. A disability friendly virtue ethics approach would avoid these pitfalls.

Simplican also criticizes the idea that capacities should have any bearing on one's moral worth. Her capacity contract is similar to the better-known racial contract, by Charles Mills. Just as the racial contract consists in an implicit agreement amongst white people that non-whites do not count morally, the capacity contract points to the implicit agreement among nondisabled people that people who cannot measure up to an arbitrary standard of capacity do not count morally. "The first side of the capacity contract bases political membership on a threshold level of capacity and excludes anyone who falls below" (Simplican, 2015, p. 4). Singer's assumption that to live well one must have a specific level of capacity, and not have a certain set of disabilities, falls squarely under Simplican's capacity contract.

Like the racial contract, the goal of the capacity contract is domination and disappearance. Disappearance accomplishes two objectives. First, it enables the social contract to appear universal - as if we were created cognitively equaldespite hinging on a distinction between the cognitively abled and the cognitively 
disabled. Second, in contemporary politics, this disappearance serves to contain anxiety about our obligations to people with severe disabilities and the threat they pose to societal resources. (Simplican, 2015, p. 5)

It is a little too convenient that, if Singer is right, and disabled people, especially those with more profound disabilities, are "better off dead," one implication is that we do not need to change society to make it more accessible.

I think virtue ethics, when informed by disability theory, can dodge the capacity contract by tying moral value not to any specific capacity, but to the potential to flourish. This potential is, I would suggest, part of what it means to be alive. As such, all people possess it; because it is intrinsic it cannot be removed. I am not suggesting that people should be compelled to flourish, instead I suggest that the potential to flourish is an important aspect of all people. Everyone has this capacity and it is always worth protecting and developing regardless of impairment. To kill someone at birth, as Singer recommends, is a radical rejection of potential, which I stand against.

\section{R.G. Frey}

Dishearteningly for me as a disabled philosopher, there is worse. The supposed inability of intellectually impaired people to flourish, used by Singer to theoretically justify killing infants, is used by R.G. Frey to argue that it is acceptable to perform nonconsensual scientific experiments on people with intellectual impairments. It runs as follows: Frey is keen to avoid speciesism, the term coined by Singer for an arbitrary preference of humans over animals. But at the same time Frey still wants to argue many people's lives are more important than many animals' lives. His solution is to claim that "normal" people have a higher quality of life than people he terms "defective" i.e. 
people with intellectual impairments. Such people do not have a higher quality of life than many animals and are therefore fair game for scientific experimentation:

What justifies the medical/scientific use of perfectly healthy rabbits instead of humans with a low quality of life? If, for example, experiments on retinas are suggested, why use rabbits or chimps instead of defective humans with otherwise excellent retinas? I know of nothing that cedes human life of any quality, however low, greater value than animal life of any quality, however high. If, therefore, we are going to justify medical/scientific uses of animals by appeal to the value of their lives, we open up directly the possibility of our having to envisage the use of humans of a lower quality of life in preference to animals of a higher quality of life. (Frey 1988, p. 169)

Disability friendly virtue ethics can provide a helpful antidote to this horrifying line of reasoning by emphasizing two things. First, in disability friendly virtue ethics, flourishing is not tied to any specific capacity. This undermines the notion that if you do not have a specific capacity you can't flourish and are for the chopping block. Second, experimenting on people with intellectual disabilities would be categorized as vicious because such an act of cruelty is bad for the character of experimenter and society as a whole. Imagine living in a society that allowed experiments on people with intellectual impairments. I do not think this would be a society in which anyone felt safe or could flourish. If you have an intellectual impairment it's hard to imagine living well with such a threat hanging over you. If you do not have an intellectual impairment it would also be difficult to live well. First, you might have friends or family directly under threat, and, second, you would know it would always be possible to acquire an intellectual impairment at which point you will become vulnerable. Frey is speaking theoretically here, he is just trying to refute a point of Singer's. He is not chasing disabled people with a net. However, theory does bleed into practice, and ideas like Frey's and Singer's affect the way nondisabled people understand, relate to and treat people with disabilities. 
I remember reading Frey's paper as an undergrad at the University of Victoria in Canada. My professor presented it as an interesting article with a thesis worth debating, not as an example of prejudice in philosophy. Some of my classmates were shocked by the views expressed, but about half were persuaded by Frey's logic. I wish I could say I jumped up, gave an impassioned speech telling classmates that the Nazis actually did this, conduct experiments on the disabled, and Nazis are never a good sign. Instead I just sat there, which was likely a failure of courage on my part, but I do not think courage should have been required of me. Articles like Frey's provide a good opportunity for fair-minded allies of disabled people to practice virtue by objecting to prejudice. It is always good to have allies who will speak up.

\section{$\underline{\text { Nussbaum }}$}

As with the first two philosophers, Nussbaum's worry is that her framework may lead her to conclude that people with severe dementia cannot live well or flourish. This time, the problem is that Nussbaum believes people with dementia may not be able to develop any of her core capabilities. Nussbaum is well known for her capabilities approach, which suggests all people should, in order to fully express their humanity, be allowed to develop a list of core capabilities. For purposes of my project, these capabilities include: play, imagination, mobility, rationality and life. Nussbaum, a supporter of disability rights, wants disabled people to flourish. Despite a generally well-deserved reputation for compassionate inclusiveness in her thinking, there is something quite frustrating about Nussbaum. Nussbaum reserves the option of excluding some individuals from the category of human based on their disabilities. In 
her paper "Functioning and Social Justice: In Defense of Aristotelian Essentialism," Nussbaum says of being human: "It will sometimes be very difficult to say whether a certain patient with senile dementia or a certain extremely damaged infant has enough of those basic capabilities to fall under the concept" (Nussbaum 1992, p. 26)

Although she expresses a more positive attitude towards disability than many philosophers, in my view Nussbaum still does not draw the circle wide enough.

While I agree with Nussbaum that it is great to have capabilities like memory, I do not think it is impossible to flourish without them. This debate comes down to the question: does disability automatically mean one cannot flourish? I have argued here that it does not. Having a disability, even a severe one like dementia, may mean that one lacks certain goods including memory, but this does not have to mean that one is necessarily worse off, or barred from the good life. In Chapter Two of the Minority Body, Barnes discusses the mere difference understanding throughout the chapter. She suggests one can understand disability as both a lack of an intrinsic good and not something that makes you automatically worse off. It is a mere difference. For example, on this view of disability we could say both that memory is wonderful, and it may be a shame to lose it, but acquiring dementia and living with memory loss may not be disaster. Maybe it is mere difference.

To illustrate her point Barnes draws a clever parallel between disability and pregnancy:

Consider a different case. We might, at least insofar as we think abilities like hearing and walking are intrinsic goods, also think that the ability to be pregnant and give birth - to grow a new person in your own body! —is an intrinsic good. As abilities go, it is certainly an impressive one. People who are male lack this ability. Nor is there any obvious male specific ability we can point to that compensates men for this lack. Being male is different than being female, and 
comes with some different abilities and experiences, but it's not as though there's some fantastic ability that only those of the male sex have which 'makes up for' the fact that they cannot have babies. And yet we don't tend to think that people who are male are automatically worse off, overall, than people who are female simply because they lack an ability we might count as an intrinsic good. (Barnes, p. 58)

Similarly, there is no superpower that makes up for memory loss. However, people with dementia can enjoy many things that may be part of a flourishing life, including connecting with friends and family, enjoying music and art. These pleasures remain available and can be enjoyed in new ways. This was my experience enjoying nature with my grandfather. Never have you enjoyed a flower as intensely and fully as when you see one for the first time (again). As people with advanced dementia often do, my grandfather seemed to live in the moment towards the end of his life. I think perhaps part of what motivates Nussbaum's suspicion that people with dementia may not be quite human, is that she has not had the chance to spend time with people like my grandfather, who have dementia and are flourishing.

It might be objected that many people with dementia struggle very much with the disability and are not flourishing; it might be pointed out that some people with early stage dementia are even suicidal. I do not for a moment deny that dementia can be very challenging both for people with dementia and for their families but in any situation where a person with dementia is angry, violent, heartbroken or suicidal, I think the first question to ask would be why? And the answer "because they have dementia" would be insufficient. It would be important to devote more resources into finding out why, what was going on in that individual's life to make them feel that way, and if possible make it possible for them to flourish once again, as a person living well with dementia. 
Fear of, and Separation from Disability

Yes, having a cognitive impairment, or any impairment or disability, might mean that flourishing would look different for you than for a nondisabled person, but it is a big leap to assume, as I have noted some philosophers do, that cognitive impairment or disability generally must preclude flourishing. This failure of imagination may have its origins in the reality that disabled and nondisabled people do not always know each other well, or at all. This disconnect between disabled and nondisabled people has its origins in comparatively recent history. Unfortunately, for the past couple of centuries the history of disability has largely been one of institutionalization. This is especially true of people with intellectual disabilities who were historically (and remain to this day) amongst the most institutionalized of disabled people. This point is neatly summed up in Academic Ableism:

For most of the 20th century, people with disabilities were institutionalized in asylums, 'schools' for the 'feeble-minded' and other exclusionary institutions, locations that became the dark shadows of the college or university, connected with residential schools, prisons, quarantines, and immigration stations in these shadows. (Dolmage, p. 3)

In The Capacity Contract, Simplican discusses the fear that nondisabled people can have of disability. She suggests that while it is true that some of this could arise from fear of becoming disabled, part of the problem is also a failure to see the positive possibilities disability can entail. Simplican argues that trying to refute fear of disability by reminding nondisabled people that we are all fragile beings likely to become disabled at some point is helpful, but not the only, or best, antidote to fear of disability. "We see this challenge in disability rights activists' popular term TAB, 'temporarily ablebodied,' disability and queer theorist Robert McRuer explains, "Sooner or later, if we 
live long enough (so we often say), we will all become disabled" (Simplican, p. 48). This approach, in Simplican's view, can help people to see themselves in the other they fear, but it does not show them the possibility of living well with, and not despite, disability. Simplican suggests that "Rather than further encode disability as the ontological sign of human limitation and decay, we could instead use disability to see the ways in which we are 'bursting with possibilities and capabilities"' (Simplican, p. 48). In my view, the failure on the part of philosophers like Singer (and to a lesser extent Nussbaum) to see anything positive in disability is a failure of imagination.

In Academic Ableism, Jay Timothy Dolmage suggests that asylums are akin to a "through the looking-glass" inversion of the post-secondary education system, containing and separating from society the "feeble-minded," regulating intellectually impaired people inversely to the ways in which knowledge is regulated and controlled within a university. (Dolmage, p. 3) It is possible that for academics, both the long separation between disabled people and nondisabled people and the extra emphasis placed on intellectual ability in universities, make scholars particularly susceptible to imagining intellectual impairment as a catastrophe.

\section{Section 2: Virtue with Disability, it Can be Done}

In Chapter 1, I defined virtue as to take pleasure throughout life in living and/or acting morally in a way that encourages one's own flourishing, and the flourishing of others. I suggested that virtue is not static, but shifts based on the virtuous person's situation, capacities and/or disabilities. 
In general, when it comes to achieving virtue, I think disability, including intellectual disability, is just another factor which goes into determining where the mean of virtue lies for you. Aristotle himself notes that it makes sense to change one's behaviour based on individual characteristics. He gives an athletic example, pointing out that different bodies require different amounts of food to help them get fit.

If ten pounds are too much for a particular person to eat and two too little, it does not follow that the trainer will order six pounds; for this also is perhaps too much for the person who is to take it, or too little - too little for Milo, too much for the beginner in athletic exercises. The same is true of running and wrestling. Thus a master of any art avoids excess and defect, but seeks the intermediate and chooses this - the intermediate not in the object but relatively to us. (NE 1106b1-7)

Building on Aristotle's example, I would argue that the mean of virtue, is relative to the individual, varying with characteristics, including disability and impairment. Disability is just one of many factors which affect where the mean lies for individuals.

However, there are two cases in which impairment may affect a virtuous agent more markedly. First, if someone's intellectual impairment is very severe, virtue may be present only in potential or be invisible to others. Second, some intellectual disabilities may make vice, in the Aristotelian sense, impossible. First, if someone is in a coma, possibly unable to feel the right way at the right time, they may not be able to be virtuous; but more importantly, we are not able to tell. It may be that someone in a coma is responding to connection with family and friends, in the right way at the right time for the right reasons. It would therefore, I think, be a mistake to count out entirely, as a virtuous person, anyone with whom communication is difficult or impossible.

Second, Aristotle understands that not everyone is ethically responsible for their actions. Actions undertaken in ignorance or due to physical or mental illness are not blameworthy or vicious, although they are failures of virtue, "since excellence is 
concerned with passions and actions, and on voluntary passions and actions praise and blame are bestowed, on those that are involuntary forgiveness, and sometimes also pity..." (NE 1109b30-35).

For Aristotle actions done in genuine ignorance are not blameworthy. He has a playful example:

But of what he is doing a man might be ignorant, as for instance people say 'it slipped out of their mouths as they were speaking', or 'they did not know it was a secret', as Aeschylus said of the mysteries, or a man might say he 'let it go off when he merely wanted to show its working', as the man did with the catapult. (NE 1111a8-10)

In short, in order to be vicious, one needs to be able to know what the right thing to do is and choose not to do it. While this is possible for some intellectually impaired people, of course it isn't possible for all.

In The Fix there is an interesting example of disability affecting virtue and vice. Fred, a person with dementia, strikes out at Kenroy (one of the carers), who is in a mad rush to get everyone cared for on time. Usually this would be vicious, but, “...all Fred knows is that a stranger is trying to pull down his pants and he doesn't like it. Kenroy knows he has 11 people to be toileted, served snacks, moved from the lounge to dining room, spoon-fed dinner, returned to the lounge, offered juice, walked to rooms, washed, toileted, and put in bed" (Welsh and Risling, p. 3). I would suggest, in this case, that Fred is not being vicious because he does not know Kenroy is trying to help. In fact, striking out at Kenroy is understandable given Kenroy's actions and Fred's condition. The solution was emotional engagement, slowing down to connect with Fred's experience. Rather than dismissing his reaction as irrational or vicious, Kenroy slowed down and connected with Fred in the moment: 
Kenroy just doesn't want to get hit. The fastest jab belongs to Fred, who doesn't understand why Kenroy wants to pull down his pants and change his briefs. He gets scared and defensive. His tough side emerges, maybe from his years as a civilian mechanic with the Pakistani military, and he punches Kenroy. Kenroy has been listening and learning. He decides there's a better way. So one day in late August, he does what his original training forbids. He hugs Fred. A big bear hug. Fred hugs him back. "Let's go to the toilet Fred," he says. They walk down the hallway, arm in arm." He hasn't hit me since," Kenroy says. (Welsh and Risling, p. 12)

I would suggest both Fred and Kenroy achieved the mean of virtue relative to their situations and characters.

Although I think The Fix gives a paradigm example of living well with dementia, it might be objected that this is but one example, and as Aristotle says, "one swallow does not make a summer". I would reply that my focus on The Fix is not due to any scarcity of examples, but a desire to go in depth with one. There is a wide body of literature on living well with dementia and how this should be best achieved. For instance, the 2018 Lancet article entitled "Living Well with Dementia" makes it clear that flourishing with dementia is not merely possible but an exciting new Horizon: “...these and other similar projects are recognising that life does not stop with a diagnosis of dementia: with the right support, living well is not tokenism, it is possible" (Morgan 2018, p. 306-307). The article goes on to give many examples of flourishing with dementia, from both formal studies and informal anecdotes; the importance of music and staying connected with community is emphasized. "Living Well with Dementia" also outlines more specific ways of flourishing with dementia, including going to the movies and even going on adventure holidays with the British organization, Dementia Adventure. The article concludes, "people living with dementia can continue to live well life does not need 
to, nor should it, end with a diagnosis" (Morgan, p. 307).

Aristotle is clear that not every failure of virtue is vicious. In rare instances when people may be unable to find the mean of virtue as a result of disability, Aristotle would not assign blame but rather understand that some actions are out of an individual's control.

Aristotle thinks there is more than one way to get into a state where you cannot be virtuous. One can be brutish, incontinent or unwell. The incontinent person knows what the right thing to do is but fails to do it, led astray by unhealthy pleasures. A brutish person was once able to distinguish between virtue and vice but has lost the ability to do so through bad behaviour. An example might be a non-alcoholic choosing to drink to excess and then driving drunk. Sober, they would not put others at risk but they lose their ability to be virtuous, through vice. Someone who is unwell may act in a way contrary to virtue due to their mental or physical illness, in which case they do not deserve blame:

These states are brutish, but others arise as a result of disease (or, in some cases, of madness, as with the man who sacrificed and ate his mother, or with the slave who ate the liver of his fellow), and others are morbid states resulting from custom, e.g. the habit of plucking out the hair or of gnawing the nails, or even coals or earth, and in addition to these paederasty; for these arise in some by nature and in others, as in those who have been the victims of lust from childhood, from habit. (NE $1148 \mathrm{~b} 25-35)$

On rare occasions when people cannot be virtuous due to illness or trauma, they do not deserve blame, but understanding, support and compassion. Aristotle is surprisingly understanding regarding mental illness, pointing out that some people trapped in cycles of abuse may not be responsible for their actions, a still controversial but compassionate insight. I suspect that there are very few people who cannot be 
virtuous at all, but for those who cannot, I think it is important to respect the potential for virtue that will be present in any person and support them in recovering or developing the capacity to be virtuous.

\section{$\underline{\text { Stronger together }}$}

It would be a mistake to discount the virtue of intellectually impaired people because they need help to achieve virtue. The distinction between a normal need for help and an excessive need for help does not survive close examination. Some of us have needs so common that they may seem invisible, but the fact is we all depend on and need each other. Of course, individuals play a large role in their own decisionmaking, but we are deceiving ourselves if we think we do it all on our own.

Modern disability theory and Aristotelian virtue ethics share the insight that individual independence throughout life is illusory. As Deborah Stone puts it in the foreword to Disability and Political Theory, “...we all need help, and we need it all the time" (Stone 2016, p. xiv). Accordingly, it is not logical to argue, as one might, that intellectually impaired people cannot be virtuous because they cannot achieve virtue on their own. No one does. We all need help, including help learning to be virtuous.

In Aristotelian virtue ethics, the ideal is to train to be brave, generous, honest and so on. Then, when you find yourself in a situation that calls for courage, honesty or generosity, you will simply act bravely or honestly without having to think about it, and you will enjoy doing it: "Not only is a horse pleasant to the lover of horses, and a spectacle to the lover of sights, but also in the same way just acts are pleasant to the lover of justice and in general excellent acts to the lover key of excellence" (NE 1099a8- 
12). If you have to think it through, you are doing something laudable, but you have not quite yet achieved the virtue you are aiming for. Rationally thinking through what one ought to do is only part of making a good ethical decision and not even the most important part. Consider this quote from Disability and Political Theory:

But no one lives without being helped, all the time, in everything we do. Every time you walk in a pair of shoes, read a book, use a computer, ask a friend for advice, drive a car, borrow a tool, make hot oatmeal for breakfast, send a text, use your bank account, or vote in an election, you are being enabled by the thousands of people who made such activities possible for you, some of them no longer living, some of them living on the other side of the planet, some of them people you might not dream of inviting to your home. They're all helping you and you couldn't live your life without them. (Stone, p. xiv)

It is normal to need help in all areas of life, including learning and achieving the virtues.

The ability to be virtuous depends much more on the chance to get a good education and live in a functional society than it does on intellectual capacity. "Hence we ought to have been brought up in a particular way from our very youth as Plato says so as both to delight in and to be pained by the things that we ought; this is the right education" (NE 1104b15).

$\underline{\text { Inclusive Metaphysics Bolsters Inclusive Ethics }}$

One might object that the capacities of those with severe impairments can never be enough to ground potential for virtue. I agree that it may not be possible for some people with more severe intellectual impairments to be vicious, yet I think to discount even the potential for virtue amongst people with intellectual impairments is needlessly exclusive and often prejudiced. This view of ethics is, I think, in part based on an unhelpfully restrictive understanding of capacity. We have a very clear image of what it means to be capable, capability is an active individual full of kinetic energy. All very 
well, but I would suggest that, at the metaphysical level, capability is more complex and people with severe intellectual impairments are capable, and this deserves recognition and respect.

In the Metaphysics, Aristotle discusses the fundamental nature of reality. He delves into the foundations of almost everything. Most relevantly for me in Book 5, Section 12 , he touches on the metaphysical nature of capacity, examining what it means to have a capacity: "We call a capacity a source of movement or change, which is in another thing or in the same thing qua other" (Metaphysics 1019a15-16).

For Aristotle, capacity resides in the person or thing that possesses the capacity. For instance, he understands musical instruments as having the capacity to be played, whereas we might locate the capacity solely in the player of the instrument (Metaphysics 1019a20-24). We might think that a musician has the capacity to play an instrument, but instruments do not have the capacity to be played. However, I would suggest that rethinking capacity in the light of Aristotle's metaphysics gives us one clear advantage. It reclaims capacity for all disabled people. If capacity always resides with that which possesses the capacity, it follows that disabled people's capacities will always be theirs and no one else's. This means that even very limited capacities such as the capacity to be physically present with friends and family, to be assisted, or to be loved, reside in the impaired person possessing them, rather than exclusively in those who spend time with them or love them or assist them.

Allow the locus of the actions to be disabled people themselves and with a simple turn of phrase disabled people take back their power. "For we say both of that which sees potentially and of that which sees actually, that it is seeing, and both of that 
which can use knowledge and of that which is using it, that it knows" (Metaphysics 1017b). Aristotle's sense of both sight and knowledge is, I would suggest, helpfully broad, clarifying that if one is alive one has both power and potential. It follows then, that if one is living one has the potential to be virtuous and flourish. One, therefore, deserves all the protections and ethical considerations that virtue ethics can give.

\section{Holding Out for Heroes}

I have noted in this chapter that there is a certain fear and aversion of disability, especially intellectual disability, present both in society and in the discipline of philosophy. This fear, I have argued, contributes to academics' doubt that it is possible for disabled people to be virtuous or to flourish. I think if there were more examples of flourishing, virtuous disabled people, in prominent positions in society and in the arts and popular media, both disabled and nondisabled people would have an easier path to virtue and flourishing. People with disabilities would have a template for virtue, familiar and exciting to them, based not in trite inspiration or stereotype, but in true moral excellence. There must be examples out there, both in books and movies, of virtuous flourishing disabled people, although it may be telling that none spring to mind. Disabled people need to grow up learning from both non-disabled people and from one another. There should be disabled role models to learn virtue from, and disabled heroes and heroines of fiction to emulate. As Oliver notes in Understanding Disability, there is a dearth of role models for disabled people to follow:

There were no disabled role models, heroes and heroines who could link my growing awareness of inequalities and injustice, and my own growing sense of moral outrage, to my experience as a disabled person, nor, indeed, to the experience of disabled people generally. (Oliver, p. 21) 
Oliver goes on to note that there seems to be an almost deliberate effort on the part of society to separate disabled identity from political identity. I agree. I too have encountered this pressure to separate myself as a disabled person from myself as a political actor. I think that working towards being a virtuous person is a political act, one based in self-respect, pride and the valuing of justice in one's community.

In my view the comparative lack of disabled role models remains a problem and a disadvantage. This problem is pronounced in film, an art form where many people find heroes to emulate. In fact, in contemporary films, we are much more likely to see disabled villains who encourage prejudice and obscure the path to virtue, than positive examples of disabled heroes. Even contemporary movies with powerful progressive messages can have worrisome representations of disabled people. Wonder Woman and Black Panther, two ground-breaking and otherwise excellent movies both feature disabled villains. This is not in and of itself bad, but in both films, and especially Wonder Woman, disability and being a villain are fundamentally linked in familiar and disturbing ways that reinforce the idea that disability is scary and the good life is out of reach for those cursed with disability.

In Wonder Woman, a major villain, the twisted evil chemical weapons designer, Dr. Poison, has a serious facial disfigurement, which both motivates and explains her misanthropy. Black Panther features a minor villain, Claw, a gleefully evil arms dealer cum assassin who is an amputee. What a surprise, his prosthetic arm sinisterly conceals a powerful miniature cannon, 'subtly' revealing, I suggest, nondisabled fear that disabled people are hiding something and clearly up to no good. 
In his classic 1985 article "Screening Stereotypes", Paul K. Longmore, sums up why it can be worrying to have disabled villains in films:

Giving disabilities to villainous characters reflects and reinforces, albeit in exaggerated fashion, three common prejudices against handicapped people: disability is a punishment for evil; disabled people are embittered by their 'fate'; disabled people resent the nondisabled and would, if they could, destroy them. (Longmore 1985, p. 32)

Dr. Poison, the villain in Wonder Woman, hits all three of these worrying points. Her facial scarring is the result of her sinister experiments: a disability is what you get for being so evil. Bitter as wormwood, Dr. Poison believes no one can appreciate her given the way she looks; so evil will be her only companion. Vengeful and hateful, she takes particular delight in killing and disfiguring nondisabled innocence. It is startling how precisely Wonder Woman has unconsciously trotted out the three most worrisome stereotypes of disabled people identified and eloquently refuted by Longmore over 30 years ago.

Yet Wonder Woman (more so than Black Panther) is actually regressive in its portrayal of disability. Dr. Poison's disability is a modern addition for the 2017 film. It does not appear in the film's source material, "Princess Maru” Sensation Comics \#2 (February 1942). In the original comic book story, Dr. Poison is not a disabled person but a beautiful Japanese princess. Cleverly disguised as a male doctor, Dr. Poison is working on behalf of Japan, in the midst of World War II. She is still developing chemical weapons but for brainwashing, rather than murderous, purposes. Wonder Woman sees through Dr. Poison's disguise and foils her plans. The comic featured dated war propaganda and was racist, so I see why the filmmakers changed Dr. Poison, but I regret the pivot to pernicious negative stereotypes about disability. 
Despite the dispiriting treatment of disability in the two films, it is encouraging to see how enthusiastically both films have been received. The broad appeal suggests that almost everyone is excited to see the possibility of flourishing in a way specific to being black or being a woman. Both the films prominently feature idealized worlds in which black people and women flourish. The fictional lands of Hemyscira and Wakanda are both remote utopias safe from prejudice and hatred that produce great heroes, who, in the tradition of heroes, save the day.

There is no world famous equivalent to Wonder Woman or Black Panther for disabled people. I regret the lack of a disabled superhero not because I think disabled people should aspire to be superheroes, such a demand would reinforce stereotypes that disabled people must be either inspirations or objects of pity, but because the absence of truly well-known disabled heroines and heroes constitutes a block to flourishing. The exciting opportunity to see oneself reflected, for once, and at long last positively and proudly in a hit film, is still denied disabled people. Maybe disabled heroes are on the way. 


\section{Chapter 4}

\section{Aristotle and Disability: Uneasy Companions}

$\underline{\text { Introduction }}$

At its core, disability friendly virtue ethics is an argument for an accessible society in which everyone can flourish and be virtuous. Throughout this work, I have drawn on Aristotle to argue for an Aristotelian inspired virtue ethics which places disability at the centre of the good life for individuals and societies. I have suggested virtue and flourishing are possible with disabilities. More than that, I have argued that there are virtues unique to disabled people which are valuable for everyone and that disabled people can express the classic Aristotelian virtues, but make them their own.

\section{Section 1: Disability Friendly Aristotle?}

You may be thinking, great, but didn't Aristotle say something about leaving disabled infants on a windswept crag to die of exposure? And wasn't there something about natural slavery in there too? Yes. Both of these bad ideas are part of the Aristotelian canon, clearly articulated in The Politics, Aristotle's treatise on political life and good governance. Aristotle suggests deformed newborns should be left out in the elements to die. And Aristotle argues that since some people, possibly particularly those with intellectual impairments, are naturally slavish, it is best for everyone if such people are slaves. Given these explicitly expressed views, how can I use Aristotle as a positive source of inspiration? In this final chapter I will address the question. 


\section{Natural Slavery}

In the Politics, Book 1, Aristotle discusses and defends natural slavery (1253b11255b15). He argues slavery is just when enslaved persons are natural slaves, that is, fitted by nature to be slaves. Slavery, according to Aristotle, is mutually beneficial. The slave gets guidance in reaching what limited potential is possible for them; a natural slave is defined by a stunted ability to flourish, and a lack of capacity for intellectual work [so prized by Aristotle]. The master of course, gets their labour. It does not seem to have occurred to Aristotle that this bargain is one-sided and unfair.

In the Politics, Aristotle is interested in establishing what a good society should look like, how it should be governed, what good citizens should be, and how they should interact with each other. He focuses mainly on small city states like Athens. He takes an exploratory approach, giving his own view on what a good society should be, while interacting with the views of other thinkers and common opinion. Throughout, Aristotle is working to understand and prescribe how good citizens should live.

For Aristotle the distinction between master and slave is an important element in the ideal household. Slave allows master time to think and philosophize without worrying about the hundred and one tasks that keep a house running — all of them, in Aristotle's view, beneath the dignity of a master. Aristotle thinks it is in the best interest of master to treat slave well. In Aristotle's mind the slave is a kind of extension of the master, an animate tool. However, slavery can be unjust, as when it is in doubt that the party enslaved is truly a natural slave. For instance, if a group is enslaved by force, slavery may not be just if the enslaving party is just stronger and not better than the 
people they enslave. Yet, importantly, Aristotle has convinced himself that it can be just to invade and enslave a group of people if they are natural slaves. The quotation below gives a good sense of Aristotle's argument.

Again, the male is by nature superior, and the female inferior; and the one rules, and the other is ruled; this principle, of necessity, extends to all mankind. Where then there is such a difference as that between soul and body, or between men and animals (as in the case of those whose business is to use their body, and who can do nothing better), the lower sort are by nature slaves, and it is better for them as for all inferiors that they should be under the rule of a master. (Politics 1154b1326)

In Book 1 of the Politics, Aristotle clarifies further: "Mind is by nature lord and master, and that which can with its body give effect to such foresight is a subject, and by nature a slave; hence master and slave have the same interest" (Politics 1252a30-32). Aristotle here may imply that people with intellectual impairments are natural slaves. To me, this sounds like Simplican's capacity contract in action. For Aristotle, if you have your wits about you, you can go free. If not, you may well be slavish by nature. Aristotle is buying into the idea that certain capacities are required to have privileges. As I have pointed out in previous chapters, Simplican sharply critiques this notion. However, in my view it is unclear whether Aristotle means people who are born disabled or with intellectual impairments are natural slaves or simply people born into positions that make it impossible to learn virtue. Either way Aristotle's willingness to subjugate a certain set of people and deny them the chance to flourish is wrong.

Aristotle comes frustratingly close to arguing against natural slavery, asking "But is there any one thus intended by nature to be a slave, and for whom such a condition is expedient and right, or rather is not all slavery a violation of nature?" (Politics 1154a1820). Unfortunately, Aristotle quickly dismisses the possibility: "There is no difficulty in 
answering this question, on grounds both of reason and of fact. For that some should rule and others be ruled is a thing not only necessary, but expedient; from the hour of their birth, some are marked out for subjection, others for rule" (Politics 1254a21-23). He is not wrong, some people in Aristotle's time and ours are born into subjection, slavery or lives of conditions of such limited opportunity that they may as well be slaves. It is slavery in all but name. Aristotle's mistake, also present in some modern thinking, is in thinking this is okay. He accepts that some people should not be allowed to flourish fully, when he should have argued that everyone get the opportunity to flourish fully as a human being.

I would suggest that even by the standards of his own ethics Aristotle's defense of slavery is morally wrong. Throughout this work I have favoured an interpretation of Aristotle that understands his Golden mean of virtue as relative to the virtuous agent as a person, whoever they may be. Aristotle ought not to say "natural slaves" as a class of people cannot be virtuous or live well, as it does not make sense to bar any class of people from virtue or the good life. Because virtue is both consistent and relative to the individual, there will be, at the very least, potential virtue, achievable by everyone including those Aristotle describes as "natural slaves".

Gottlieb has a very similar perspective. She argues that if Aristotle's mean is relative to the virtuous individual's personal characteristics, he has no business excluding women or slaves from full virtue:

However, if the more complicated account of Aristotle's views is correct, Aristotle's doctrine of the mean precludes him from making his egregious comments about women and slaves for the following reason. If being a woman or slave is a particular fact about someone, on the lines of Aristotle's discussion in his Nicomachean Ethics, it ought to be relevant on some occasions and not on others. But it is always relevant according to the account in the Politics and the 
Nicomachean Ethics \{Pol. I 13 i26oa28-33; EN VIII 121 i62a2 5-7), which means that Aristotle is misapplying his own theory. Being a woman and being a slave may certainly be relevant factors in some instances of moral reasoning, but they should not be invariantly relevant factors. (Gottlieb, p. 31-32)

Being enslaved or being a woman may shift where the mean of virtue lies for you, but it does not mean that you cannot be virtuous. Aristotle does think that it is possible for natural slaves and women to flourish as much as their, in his view "stunted" natures allow, in order to fulfil their natural subservient functions. For slaves, this is to be virtuous only to the extent that they need in order to carry out their duties as slaves; for women, the virtues are to be loyal and subservient wives and as quiet as possible (Politics, 1260a15). As I have mentioned earlier in this work, I do not share Aristotle's certainty that there is a human nature, I am even more suspicious of his belief that there is a woman's nature and completely disagree with his idea of a slavish nature. Additionally, Aristotle mistakes cause for effect: it is not the nature of women and "natural slaves" to be unable to express virtue fully. It is circumstances, not nature, holding them back. Moreover, if the institution of slavery is allowed to destroy an individual potential for virtue, this should be, I would argue, an evil within an Aristotelian virtue ethics framework, not an excuse to keep people enslaved.

\section{How Should We Respond to Aristotle's "Natural Slavery"?}

It may be inconsistent of Aristotle to denigrate women and arguably, categorize people with cognitive impairments as natural slaves, but he did. How should we respond? Some helpful answers can be found in the book Feminist Interpretations of 
Aristotle, which includes Ruth Groenhout's paper “The Virtue of Care.” Groenhout suggests Aristotle can be valuable to feminists despite his sexism. She notes "Feminist criticisms of Aristotle are so extensive one might wonder whether a feminist should waste her time on his work" (Groenhout 1998, p. 171). She goes on to argue there are insights of value to feminists in Aristotle's work. Two of these advantages struck me as relevant. First, Groenhout mentions that Aristotle critiques a sharp separation between reason and emotion, arguing instead that emotion is an important part of ethics:

For one thing, his ethical theory offers an account of ethical reasoning that incorporates the emotions as essential to adequate rationality, rather than assuming that the two are inevitably opposed. Such an opposition has been harshly criticized by many feminist thinkers. (Groenhout, p. 172)

I suggest this insight is valuable to disability advocates as well as feminists. Disabled people, like women, have sometimes been criticized for not being able to untangle emotion from reason. Aristotle provides a helpful counterargument, pointing out that reason and emotion should not be untangled. Rather, in ethics, they should work together.

Second, Aristotle is clear that circumstances, social connections and individual characteristics matter in ethics. According to Groenhout, Aristotle's focus on particularity can make him a useful resource for feminists:

Aristotle also has an ethical theory that seems congenial to feminist conceptions of the self as situated, particular, and enmeshed in social relationships, because his theory recognizes the particularity and situatedness of ethical decisionmaking and because it recognizes the extent to which human nature is inescapably social. (Groenhout, p. 172)

In my opinion insights like the ones Groenhout points to outweigh Aristotle's misogyny and prejudice against disability. Those sharp edges are still there, but it's worth navigating through them to reach insights of value. Aristotle's recognition of 
human interconnection is shared by disability culture and formally discussed in Disability Studies. In my view the mean of virtue can and should shift based on the virtuous disabled person's individual characteristics including their impairment.

\section{Aristotle and the Exposure of Deformed Infants}

Perhaps the most chilling sentence in all of Aristotle's work from a disability perspective is: "Let there be a law that no deformed child shall live." (Politics 1335b1921) This single sentence is all Aristotle says on the topic in Book 7. Short as this line is, it is concerning enough to deserve full examination. The sentence is not focused on or explored. Aristotle, it would seem, did not consider this remark the ethical bombshell it appears to contemporary readers. There may be cultural reasons for Aristotle's casual approach. For Aristotle, the line between abortion and infanticide may not have been as clear and morally relevant as it is for most thinkers in the twenty-first century.

In her grim but interesting paper, "Not Worth the Rearing," Cynthia Patterson notes that although in ancient Athens there was a moral and intellectual distinction between abortion and infanticide, this line was not clear-cut. "It can at least be said that Greek terminology suggests a view of exposure of the newborn as essentially distinct and different from the killing or harming of a child who is a recognized member of a family" (Patterson 1985, p. 106). According to Patterson, infants in ancient Athens may not have been considered truly people or part of the family, until about the first two weeks of life had passed. The exposure (exposing an infant to the elements, with the expectation of death) of very young infants may have been considered morally equivalent to the abortion of a foetus, rather than equivalent to killing a child in cold 
blood. If Aristotle did not see a sharp moral distinction between foetuses and newborn infants, exposure might be, in Aristotle's mind, part of his discussion on abortion. Indeed, a brief discussion of abortion immediately proceeds Aristotle's remark on exposing deformed infants. Aristotle states that abortion may be acceptable under some circumstances, when a family has too many children already and the pregnancy is not too far advanced (Politics 1335b20).

The possible moral porousness between infant and foetus in ancient Athens discussed by Patterson might help to explain Aristotle's "stating the obvious" tone. However, I do not think any amount of ancient Greek waffling about the moral status of infants excuses Aristotle. He is still too glib by half in this line: he is talking about who should live and who should die. One line is not sufficient. Aristotle does not specify what he means by "deformed," but it seems clear he is referring to children with unspecified physical disabilities. If he is suggesting that disabled children should not be allowed to grow up, he implies that the disabled life is not worth living and aggressively devalues disabled people. It is also troubling that Aristotle envisions a good state as one in which killing disabled children is mandated by law. But is it fair to draw a straight line between deformity and disability? I think, yes, there is enough in common with Aristotle's deformity and modern disability to warrant a connection between the two, but not a one-to-one correlation.

For Aristotle, "deformity" refers to innate or acquired features of living things that stop or interfere with normal functioning. Deformities are primarily physical. For example, in The History of Animals, Aristotle refers to the residual eyes of moles, describing their underdeveloped eyes as a natural defect or deformity: 
For in point of fact it cannot see, and has no eyes visible externally; but when the outer skin is removed, it is found to have the place where eyes are usually situated, and the black parts of the eyes rightly situated, and all the place that is usually devoted on the outside to eyes: showing that the parts are stunted in development, and the skin allowed to grow over. (History of Animals 491d2735)

This gives a good sense of what Aristotle means by deformed. He understands the underdeveloped eyes of moles as a failure to reach the full potential of a wellfunctioning eye. This failure of function is a deformity. We can therefore deduce that when he says "deformed" children should be exposed, Aristotle means children or infants with physical features blocking what he considers "proper" functioning and flourishing. Modern disability is a much broader category, although it can include people with unusual physical characteristics, analogous to those Aristotle calls "deformities."

In English the word "deformed" has a horror film edge, bringing half-formed images of "misshapen" human features to mind. However, it is unclear if in the sentence, "let there be a law that no deformed child shall live," the word "deformed" is the perfect translation. Here Aristotle is moving quickly, his tone scientific. I think he is working to convey that these children are, in his view, damaged; the unsettling connotations of the word deformed may owe more to the translator's fears than Aristotle's prejudices. The word deformed is not the only possible translation for

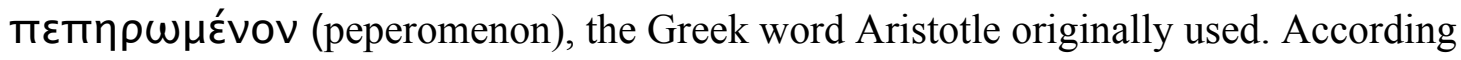
to the Liddell-Scott Jones online dictionary, peperomenon is the past tense of the Greek verb pero-o meaning to maim or mutilate, especially in the limbs. It can also mean “incapacitated" (Perseus E-Dictionary). 
Interpreting the Line, "let there be a law that no deformed child shall live"

Aristotle might be thinking that deformed infants would not be good citizens and should be put out of the way. Or Aristotle could be concerned about the suffering of "deformed" infants given the relative lack of neonatal care in his time. Each interpretation is worrying. If Aristotle thinks "deformed" children do not belong in society, he thoroughly devalues the lives of disabled people. If he is worried about suffering, Aristotle may be thinking disabled lives are uniformly ones of misery: a mistaken belief still current. Whether Aristotle is interested in the reduction of suffering or guaranteeing the best possible citizens is unclear. Perhaps Aristotle's motivation is a little of both.

Aristotle's statement in favour of exposing deformed infants, may be based more in a recognition of their short odds of survival than a concerted desire to wipe out disabled people as a class. I cannot know for sure why Aristotle said what he said, but to me Aristotle does not seem actively opposed to any disabled people surviving. A low bar to be sure, but one that not all academics, present or past, can clear.

In Aristotle's History of Animals: A Treatise on Animal Biology, he discusses birth and the early infancy of animals, including human beings. Aristotle refers to high human infant mortality in the first week of life: "The majority of deaths in infancy occur before the child is a week old, hence it is customary to name the child at that age, from a belief that it has now a better chance of survival" (588b7-10). Aristotle likely perceives an increased risk of death in the first days of life for "deformed" children, being aware how risky the first days of life were for nondisabled infants. He probably also knew this risk would be heightened even further for "deformed" children. This recognition of very 
high mortality risk may have motivated his endorsement of exposing "deformed" children.

Another point suggesting that Aristotle does not object to the survival of any infant with a hint of disability is his positive treatment of midwives saving weak infants:

It often happens that the child appears to have been born dead when it is merely weak, and when, before the umbilical cord has been tied the blood has run out into the cord and its surroundings. But experienced midwives have been known to squeeze back the blood into the child's body from the cord, and immediately the child that a moment before was bloodless came back to life again. (History of Animals 587)

Perhaps when Aristotle says "deformed" children, he has what he would consider hopeless cases in mind. There may be some overlap between weak infants and disabled infants. Again, I suggest that our modern category of disability and the ancient Greek category of deformed are distinct.

\section{Section 2: The Myth of Progress}

Before I read Aristotle's passages on midwifery I assumed medicine before the twentieth-century was rudimentary at best. Yet Aristotle seems to be giving a nod to the skill and expertise of midwives. "The cutting of the navel-string, which is the nurse's duty, is a matter calling for no little care and skill" (History of Animals 587a10). Many of us have a sense that things are getting better as history progresses, especially for medically fragile people like disabled infants. I think this is an assumption worth questioning. Because a sense of the ineptness of historical medicine has trickled into popular culture, perhaps with a particular focus on the ineffectiveness of medieval humoral medicine associated with Aristotle, it is easy to wrongly assume an unbroken 
progression in medicine from uniformly appalling in ancient times to unfailing excellence in modern times.

In my view, Aristotle should have noticed the potential for flourishing present in the children he classifies as "deformed" and encouraged the development of this potential rather than arguing for it to be snuffed out. Yet it is hard for me to work up too much of a head of steam regarding a single repugnant sentence by Aristotle when we have so much detail and passion from modern philosophers, on almost the same subject. I have noted that Singer supports, in some circumstances, killing disabled infants. Singer devotes much more time to this position than Aristotle ever did and provides much more complex arguments. Yes, Singer is speaking only in theory, while disabled infants were exposed in real life in ancient Greece. However, it is a mistake to think that either the attitudes that led to exposure of disabled infants or practices similar to exposure are long dead.

Modern equivalents to the exposure of disabled infants

Dr. Udo Schuklenk, in his 2015 article "Physicians can justifiably euthanize certain severely impaired neonates", argues that doctors should be allowed to kill some severely disabled infants, if their parents agree. The short paper is heavy with jargon, obscuring the basic premise, that it is right to kill some children at birth. Even the title needs translation. I suggest it should read: "Doctors may morally end the lives of some severely disabled infants." "There appear to be some cases, then, where continuing existence is not in a severely impaired neonate's best interest. Terminating its life, based on parent choice, seems a prima facie reasonable option" (Schuklenk 2015, p. 535). In 
other words, sometimes, continuing to live is, according to Dr. Schuklenk, not good for some severely impaired infants. In these cases, it makes sense to end their lives, if the infant's parents agree. Note the use of "It". I suggest this is dehumanizing, we call things that are not human "It". There is not as much distance as one might hope between Aristotle and Dr. Udo Schuklenk, or Singer on the question of killing disabled infants. Dr. Schuklenk has three criteria for making the choice of which severely disabled infants should be killed. I think they are worth exploring and critiquing here.

1. Will this child have a quality of life, that makes living worthwhile?

"We would ask questions such as: Does this baby have the capacity for development to an extent that will allow him or her to have a life and not merely be alive? If we reach the conclusion that it would not, we would have reason to conclude that his life is not worth living" (Schuklenk, p. 535).

Dr. Schuklenk appears to be another signatory to the capacity contract, arguing that one needs to have particular capacities to have a life worth living. Throughout this work I have drawn on Aristotle and others to argue it is a mistake to define a life worth living so narrowly. Even if doctors believe they have the best interests of patients at heart, they may not be able to imagine disability and the good life coinciding. Hence, their advice is to end lives that could have been ones of flourishing and virtue.

2. Keeping severely disabled infants alive is a waste of resources.

If, a disabled infant's life is, in a doctor's view, not worth living, failing to end this infant's life is a waste of resources: "Continuing life-prolonging care for the infant would be futile, it would constitute a waste of scarce health care resources. Health care resources ought to be deployed where they can actually benefit patients by improving 
their quality of life. This cannot be achieved in the scenario under consideration" (Schuklenk, p. 536).

The scenario under consideration is, of course, the continued life of a severely disabled child. In Chapter 1, I discussed the virtues of liberality and magnificence. I argued that guaranteeing disabled people the chance to flourish by creating accessible societies may be an opportunity to exercise both virtues. Instead of implying that by just existing severely disabled babies siphon off valuable resources, Dr. Schuklenk might have argued for a liberal or even magnificent increase in resources into neonatal care for disabled infants. Dr. Schuklenk says resources are scarce. An alternative approach would be to do our best to make them less so.

3. Dr. Schuklenk's third argument is based in compassion. He argues that it is heartbreaking for families of severely impaired infants to watch their children suffer. In these cases, severely disabled infants should be killed, in part to ease the suffering of the people around them: "Why then should doctors provide assisted dying on the parents' request? They should do so because the parents and attending health care professionals' interests matter in morally relevant ways" (Schuklenk, p. 536).

Yes, there is a complex debate to be had on the ethics of euthanasia in general. However, the presence of a severe impairment often does not mean that one is suffering or dying. Dr. Schuklenk, I think, conflates disability and painful terminal illness or death here. Lastly, although his motivation is compassion, it is misplaced. He wants to ease the suffering of disabled children's parents by essentially getting rid of the problem child. I would argue a more virtuous solution would be to support the disabled infant 
and their family in leading a good life. A broader understanding of quality of life would, I suggest, be helpful.

Dr. Brian S. Donahue, disagrees with Dr. Schuklenk, writing in response:

Intentional euthanasia of infants is morally unacceptable: it advocates selective termination of life on the basis of dangerously subjective definitions, which history has shown impossible to contain. Furthermore, it abandons the hope of medical progress. Both are directly contrary to Hippocratic principles. (Donahue 2015, p. 1685)

Still, Dr. Schuklenk's position is becoming increasingly accepted as the default

progressive view. Thousands of years later, it is just a hair's breadth away from Aristotle on the exposure of "deformed infants." The only differences between Aristotle and Dr. Schuklenk are that Aristotle states that deformed infants should not be allowed to live while Dr. Schuklenk argues for a more active killing of "severely impaired neonates" (Schuklenk, p. 2?). To his credit, Dr. Schuklenk does not argue that the killing of disabled infants should be mandated by law, as Aristotle does. Dr. Schuklenk believes parents should have choice in the matter.

Despite the unsettling parallel between contemporary support for the killing of disabled infants and allowing them to die of exposure in Ancient Greece, it is excessive to completely reject Aristotle as a source for disability friendly insights. He supported this appalling practice, but Aristotle's endorsement of infanticide, while deserving of reproach, is less vigourous than some contemporary arguments in favour of infanticide, as Dr. Schuklenk makes abundantly clear. Today, disabled infants are sometimes legally killed, because of impairments, and, as Dr. Schuklenk notes, it is legal to end the lives of severely disabled infants in the Netherlands and elsewhere. If Aristotle's sentence "let there be a law that no deformed child shall live" stops you cold, and you wish to have 
nothing more to do with a philosopher who defended infanticide, I can understand this. But I think we would lose more than we would gain by dismissing Aristotle as a resource for disability friendly work because of one unjustifiable sentence.

History of prejudice against disability, over centuries. Fear builds

In the last three centuries there is been a steady increase in fear of disability. Comparatively recently disability has been more rigorously classified and thoroughly worried about, at least in the Western context, than in earlier history. Simplican discusses the heightened construction of intellectual disability in the eighteenth-, nineteenth- and twentieth-centuries. She notes that at this time, medical professionals felt an increasingly urgent need to classify, control and eliminate disability. "The compulsion to classify disability transgresses the border between human and animal as a way to instill community boundaries that help buttress theories of racial and increasingly gendered inferiority" (Simplican, p.58).

In Chapter 2 of The Capacity Contract, Simplican discusses several thinkers whose ideas are redolent with prejudice against and fear of disability, including those of John Langdon Down and Henry H. Goddard. Down, the nineteenth-century doctor after whom Down syndrome is named, unflinchingly compared people with Down syndrome to monkeys and advocated for the universal institutionalization of people with Down syndrome, including children, with or without the consent of families. He even claimed children with Down syndrome should not be allowed to play with nondisabled children. Nineteenth-century American psychologist Henry H. Goddard, an advocate of eugenics, considered disabled people a blight on society: "Not until we take care of this class and 
see to it that their lives are guided by intelligent people, shall we remove these sores from our social life" (Simplican, p. 61).

Goddard, fought successfully for the involuntary sterilization of disabled people.

Rhetoric at this pitch was not uncommon at the time. I do not think Aristotle demonstrates anything like the deep contempt, terror and hatred of disability that became the hallmark of true disability prejudice in later centuries.

\section{Eugenics}

Following Aristotle there would come many thinkers wholeheartedly committed to eliminating disability. Within living memory, many thousands of disabled people have been killed or sterilized for being disabled. Eugenics has been a particularly hostile force in the lives of many disabled people. The idea of encouraging the best amongst us to have children is old and would not have been unfamiliar to Aristotle. But true eugenics did not exist until the 1880's, when British scientist Francis Galton coined the term “eugenics" in 1883. Galton drew on recent scientific advances to develop his views, especially the new science of evolution and effective selective breeding in farming. Eugenics refers to seeking the healthiest population of human beings by selective breeding. Judith Daar gives a crisp definition The New Eugenics:

Eugenics includes selection on the basis of genetic characteristics and stems from the belief that human beings or humanity can be improved by encouraging people with desirable traits to have children and by encouraging people with undesirable traits not to procreate. (Daar 2017, p. 1)

The category of "less desirable" people varies, but always includes people with intellectual and physical disabilities. 
The intensity eugenic thinking has brought to the persecution of disabled people is remarkable; horror of human frailty and impurity poured into the burgeoning field of eugenics. From the beginning, people in many nations perceived eugenic policies as a way to rescue humanity from being overrun by degenerates. In the nineteenth- and early twentieth-centuries eugenics was a popular and rapidly expanding field across the globe: there was a consensus that eugenic policies were progressive. At this time many countries, including America, Canada, England, along with much of the Commonwealth, France, Sweden and of course Germany, instituted eugenics policies in laws including forbidding disabled people from marrying, forced sterilization and/or institutionalization. Nazi Germany, of course, went further, killing over 60,000 disabled children and adults in the late 1930's and '40's. The horror of disability hatred came to its peak in the Nazi imagination. Still, the end of World War II and the atrocities of the Nazis did not end eugenics. Eugenic policies continued well into the twentieth-century in many countries, including Canada, where compulsory sterilization continued into the 1970's.

The Film Board of Canada's documentary, The Sterilization of Leilani Muir, (1996) gives a human face to this Canadian experience, and a clear sense of the staying power of eugenic thinking, which fuelled forced sterilization policies in Canada and elsewhere even as late as the 1960 's. Voices were raised in earnest panic over the prospect of an influx of degenerate imbeciles into "good Canadian stock", a phrase which comes up unsettlingly often in the film. The Sterilization of Leilani Muir explores Muir's successful court case against the province of Alberta and the history of eugenics in Canada. None of this recent history lets Aristotle off the hook. Yet next to Nazi 
persecution or broad nineteenth- and twentieth-century eugenic efforts to contain or halt disability it is hard to consider Aristotle the enemy.

Infanticide in Ancient Greece, the view from Archaeology

In her 2018 dissertation The Life Cycle of Disability in Ancient Greece, archaeologist Deborah Sneed presents substantial evidence that suggests that disability was a normal part of ancient Greek life. Sneed argues compellingly that although exposure of "deformed" or disabled infants did happen, it was not a widespread or automatic occurrence. She cites examples of ancient Greek physicians writing on the care of deformed infants and refers to archaeological evidence of special care for weak and deformed infants, such as specialized drinking vessels for babies with cleft palates: "Archaeological evidence strengthens the argument that ancient Greeks did not kill deformed infants and that they occasionally attempted to accommodate a range of congenital deformities" (Sneed 2018, p. 62).

Sneed refers to instances of adults with disabilities appearing in Greek art, especially on pottery, as well as in literature, and she critiques the evidence on which the view of ancient Greece as entirely hostile to disability has built up. All this suggests that although some disabled people may have been killed as infants in ancient Greece the practice was by no means universal, and disabled people had a distinct presence in ancient Greece:

Evidence in the form of medical treatises, specialized ceramic and glass vessels, and burials of neonates suggests that parents, midwives, and physicians did not automatically abandon congenitally deformed infants and even in some cases attempted to treat, cure, and/or accommodate their special needs. We cannot pretend to know how every parent reacted to the birth of any infant, let alone a 
particular infant, but the totality of evidence paints a picture of acceptance and accommodation, not rejection. (Sneed, p. 29)

Sneed points out that disability was present everywhere in ancient Greece, from literature and religion to day-to-day life, including in the works of Homer on which Aristotle often draws:

The god Hephaistos, described as both a 'renowned craftsman' and 'lame in both legs' is mentioned 41 times in the Iliad and 19 times in the Odyssey. Hephaistos is critical to the plot of the Iliad, as he must fashion Achilles's armor, without which the hero cannot succeed, and the Greeks cannot win the war. (Sneed. p. 24)

Sneed goes on to point out that, in Greek tradition Homer is both revered as a great poet and well understood to be blind. She suggests that it is easy to assume infanticide was more common than it may in fact have been:

These claims elicit little controversy. It is easy to accept that deformed infants were unwanted and had no place in ancient society because we assume that an economy based largely on agriculture rendered impractical any investment, emotional or otherwise, in non-productive members. (Sneed, p.13) But a sensitive reading of all available evidence supports neither this conclusion nor its premises. (Sneed, p. 35)

When Sneed refers specifically to Aristotle, she focused on the same line that I did: "let there be a law that no deformed child shall live" (Politics 1335b19-21). Sneed is critical of Aristotle but emphasizes that he is working in the realm of theory. Aristotle is describing the way he thinks things ought to be not the way things are. As a result, Sneed claims Aristotle's theoretical work is not a good basis on which to make conclusions about the actual practice of infanticide in ancient Greece. It is troubling that Aristotle's ideal society would expose deformed infants, and while in my view Aristotle should not have endorsed the killing of disabled infants, it is relevant that he endorses it in theory only. 
After quoting Aristotle's line from the Politics 1335b20-22, Sneed writes:

This seems clear: Aristotle advocates exposing or outright killing deformed infants. But to what extent can we say that contemporary Greeks were, indeed, acting as Aristotle envisioned his ideal citizens would? That he is compelled to include such an explicit statement suggests, to the contrary, that the practice was not a matter of course in contemporary Greece. Both Plato and Aristotle apparently do not value the lives of certain infants and would, if they could, ordain that such infants be hidden away among the lower classes or killed. But as many have pointed out, "what Plato stipulates here for his eutopia may not be used as evidence for the practice in contemporary Athens" (van N. Viljoen 1959:63) and "Both Plato's Republic and Aristotle's Politics describe ideal societies. While a utopia mirrors reality to some extent, it is a distorted reflection" (Rose 2003:34). Neither Plato nor Aristotle describes in these works contemporary societies. (Sneed, p.46)

Sneed is critical of Aristotle's endorsement of infanticide but makes the divide between theory and practice clear. More hopefully still for Aristotle as a disability friendly resource, she draws our attention to Aristotle's positive tone as he addresses weak, likely disabled, infants:

But even Aristotle himself is occasionally less pessimistic about the fate of deformed or otherwise imperfect infants. In History of Animals (9(7). 587a20-24), for example, the philosopher, whose father was a physician, describes infants who appear dead at birth but who are "merely weak." In these cases, Aristotle says, experienced midwives resuscitate them by squeezing blood from inside the umbilical cord, where it is stuck, back into the infant's body. In some cases, this likely led to brain damage due to a lack of oxygen, but still such infants are resuscitated. (Sneed, p. 57-58).

This passage suggests that Aristotle is not implacably opposed to the survival of any disabled infants. As Sneed points out, Aristotle does not recommend killing these weak, likely disabled infants, but instead speaks positively of their resuscitation. I agree with Sneed, that this passage shows it to be simplistic to read Aristotle as hostile to disability and disabled people, based on his idea for infanticide in the Politics.

As Sneed has pointed out, there is evidence that some disabled infants were cared for in ancient Greece and that doctors, in ancient times, treated persons with 
congenital disabilities, taking such instances of human difference as normal. Disability has always been a part of the human experience. I would argue ancient disgust at this form of human difference, may be exaggerated. Sneed refers to ancient physicians who speak positively of supportive care for infants with disabilities, specifically, cleft palates, as well as underdeveloped limbs and club feet.

Hippocratic physicians, who had actual, practical experience with patients from all over the Greek world not only saw and treated congenitally deformed infants, but they also expressed active optimism about the potential capabilities of deformed infants. Although he is speaking generally, Isocrates, a 4th century BCE rhetorician, calls the exposure of infants by parents a crime of the sort that never occurs at Athens (Panathenaicus 122). It is unmethodical to ground our understanding of ancient Greeks' treatment of deformed infants in the utopian discussions of Plutarch, Aristotle, and Plato. That we accept conclusions based on such a limited range of sources reflects implicit assumptions and biases that we have about disability and deformity. (Sneed, p. 58-59)

Most of the ancient passages quoted by Sneed, too lengthy to reproduce here, have a matter of fact, breezy tone about treating disabled patients. It seems to be assumed by ancient physicians that disabled people should be treated and that disabled people can participate in society, an assumption with which Singer and Schuklenk, might disagree. I agree with Sneed that modern ideas of ancient revulsion at disability may reflect our own prejudices, more than ancient ones. Ancient Greece was no paradise for disabled people. Yet neither ancient Greece nor Aristotle were hostile to disability to such a degree that a disability friendly project cannot draw on Aristotle's ideas.

I accept that there was some aversion to disability in ancient Greece and disabled infants were in some cases exposed. I do however agree with Sneed that when we construct ancient Greece as wholly hateful towards disability, this construction of the past tells us more about our feelings regarding disability today than about thoughts and feelings towards disability in ancient Greece. Sneed is not 
alone in questioning whether infanticide was widely practiced or accepted in Aristotle's day. In his article "The Exposure of Children and Greek Ethics" Cameron argues that in fact, objections to infanticide on moral grounds originated in ancient Greece. (Cameron 1932, p.113). Like Sneed, Cameron points out that the evidence for infanticide is scant: "In the Hellenistic period...there is little direct proof of exposure...." (Cameron, p.105) He notes that the evidence for infanticide as a common everyday practice is particularly week for Athens in the time of Plato and Aristotle. (Cameron, p.106) Cameron sees Aristotle's attitude towards infanticide in the Politics as evidence of growing ambivalence towards infanticide. Referring to Aristotle, Cameron says: "This passage is important since it seems to prove that by the time of Aristotle a rational objection was felt in certain circles to family limitation by exposure of the child alive." (Cameron, p. 109) To Cameron, it is highly relevant that Aristotle's stance on infanticide is followed by a mention of abortion:

The passage reads as follows in Jowett's translation (VII. 16, 15): 'As to the exposure and rearing of children, let there be a law that no deformed child shall live. But as to an excess in the number of children, if the established customs of the state forbid the exposure of any children who are born, let a limit be set to the number of children a couple may have; and if couples have children in excess, let abortion be procured before sense and life have begun; what may or may not be lawfully done in these cases depends on the question of life and sensation.' (NE 1335b)

Cameron understands Aristotle's sentence about infanticide as support for abortion over infanticide. I find this interpretation plausible. When Aristotle says "if the established customs of the state forbid the exposure of any children who are born," he does appear to be both acknowledging that infanticide is not universally accepted, and that abortion may be morally preferable. 
The above is not the only possible interpretation of Aristotle, and Aristotle certainly gives no explicit objections to infanticide. G van N Viljoen, in "Plato and Aristotle on the Exposure of Infants at Athens" argues that the moral acceptability of exposing infants was taken for granted in ancient Greece and that Aristotle himself was clearly in favour of exposure both in the case of "deformed" infants and unwanted newborns, he writes:

In the case of deformed new-born infants, Aristotle recommends exposure without giving any indication of any public opinion opposed to this kind of exposure; in the case of excess procreations he personally by implication, apparently, also considered exposure a suitable means of limitation, but as he was conscious of a general or at any rate widely spread public opinion against this kind of exposure, he recommends a limitation of the maximum number of procreations, coupled with early abortion, as substitutes for exposure in communities where the public opinion is so opposed to it. (Viljoen 1959, p. 69)

In my view, both interpretations of Aristotle are plausible: perhaps Aristotle was all for exposing some infants, perhaps he had misgivings. What Sneed and Cameron, among others, make clear is that we cannot be certain. 


\section{CONCLUSION}

I will conclude with a brief discussion of Aristotle as the foundation of my thesis.

\section{$\underline{\text { Aristotle }}$}

I admire Aristotle. I chose to concentrate on virtues discussed by Aristotle because the virtues he focuses on are well tested and have been adopted by many traditions. That Aristotle's virtues exist in a golden mean between extremes, relative to the individual, lends flexibility. This flexibility helped me to develop disability friendly virtue ethics.

One thing I do not wish to import from Aristotle is his certainty about particular types of human nature, i.e. woman's nature and natural slave nature, which leads him to make comments that today we would fairly label racist or sexist. I do not wish to import racism or sexism into my work. My aim in drawing on Aristotle is to provide a strong moral argument against the oppression of disabled people.

I also draw extensively on disability scholarship and disability advocacy. Unlike Aristotle's ethics, part of the aim of disability friendly virtue ethics is to widen the ethical circle to include all people with or without disabilities. I agree that, as in Aristotle's original virtue ethics, true virtue is only possible when one is flourishing. I have argued that guaranteeing disabled people the chance to flourish increases the chances of all people to flourish. Disability friendly virtue ethics grounds the movement for an accessible world in a strong ethical tradition. 


\section{Bibliography}

Aristotle, History of Animals The Complete Works of Aristotle: The Revised Oxford Translation. Vol. 2, Princeton University press, Princeton, N.J. 1984.

Aristotle, Metaphysics. Aristotle, and Jonathan Barnes. The Complete Works of Aristotle: The Revised Oxford Translation. Vol. 2, Princeton University press, Princeton, N.J. 1984.

Aristotle, et al. The Nicomachean Ethics. Oxford University Press, New York, Oxford, 2009.

Aristotle, The Nicomachean Ethics. Aristotle, and Jonathan Barnes. The Complete Works of Aristotle: The Revised Oxford Translation. Vol. 2, Princeton University press, Princeton, N.J. 1984.

Aristotle, Politics. Aristotle, and Jonathan Barnes. The Complete Works of Aristotle: The Revised Oxford Translation. Vol. 2, Princeton University press, Princeton, N.J. 1984.

Albrecht, Gary L (General Editor). (2006) Encyclopedia of Disability [electronic resource]. Thousand Oaks, Calif, Sage.

Aviv, Rachel. (2018) “What Does it Mean to Die?" The New Yorker: Annals of Medicine. February 5 Issue. www.newyorker.com/magazine/2018/02/05/whatdoes-it-mean-to-die. Accessed $19^{\text {th }}$ August 2018.

Barnes, Elizabeth. (2016) The Minority Body. Oxford University Press.

Blackwell, Angela G. (2017) “The Curb-Cut Effect.” Stanford Social Innovation Review, vol. 15 , no. 1. 
Cameron, A. (1932) "The Exposure of Children and Greek Ethics.” The Classical Review, vol. 46, no. 3, pp. 105-114.

Canadian Federation for the Blind. "About Us." www.cfb.ca/about-the-cfb. Accessed $20^{\text {th }}$ August 2018

Clare, Eli. (2017) Brilliant Imperfection. Duke University Press.

Daar, Judith. (2017) The New Eugenics: Selective Breeding in an Era of Reproductive Technologies. Yale University Press.

Donahue, Brian S. (2015) "Infant euthanasia is morally unacceptable." The Journal of Thoracic and Cardiovascular Surgery, vol. 149, no. 6, June, pp. 1684-1685.

Donaldson, Sue and Will Kymlicka. (2016) "Rethinking Membership and Participation in an Inclusive Democracy: Cognitive Disability, Children, Animals.” Disability and Political Theory, edited by Barbara Arneil and Nancy J. Hirschman, Cambridge University Press, pp. 168-197.

Dolmage, Jay Timothy. (2017) Academic Ableism. University of Michigan Press.

Frey, R.G. (1988) "Moral Standing: the Value of Lives, and Speciesism.” Between the Species: A Journal of Ethics, vol. 4, no. 3, Summer pp. 191-201.

Gottlieb, Paula. (2009) The Virtue of Aristotle's Ethics. Cambridge University Press.

Groenhout, Ruth. (1998) “The Virtue of Care.” Feminist Interpretations of Aristotle, edited by Cynthia A. Freeland, Pennsylvania State University Press, pp. 171-200.

Harrington, John W. (2008) “People-First Language.” Consultant for Pediatricians, vol. 7, no. 8 . 
Johnson, Harriet McBryde. (2003) “Unspeakable Conversations.” The New York Times Magazine. August $20^{\text {th }}$. www.nytimes.com/2003/02/16/magazine/unspeakableconversations.html. Accessed 20 ${ }^{\text {th }}$ August 2018.

Longmore, Paul K. (1985) “Screening Stereotypes: Images of Disabled People.” Social Policy, Summer Vol. 15, pp. 31-37.

Longmore, Paul K., and Oxford University Press. (2016) Telethons: Spectacle, Disability, and the Business of Charity. Oxford University Press, New York, doi:10.1093/acprof:oso/9780190262075.001.0001.

McCrary, Lorraine Krall. (2016) "Hannah Arendt and Disability: Natality and the Right to Inhabit the World." Disability and Political Theory, edited by Barbara Arneil and Nancy J. Hirschman, Cambridge University Press, pp. 198-221.

Mills, Charles. (1997) The Racial Contract. Cornell University Press.

Molineux, Matthew. (2017) Oxford Dictionary of Occupational Science and Occupational Therapy. Oxford University Press. eISBN: 9780191773624. DOI: 10.1093/acref/9780191773624.001.0001. www.oxfordreference.com/view/10.1093/acref/9780191773624.001.0001/acref9780191773624. Accessed 20 $0^{\text {th }}$ August 2018.

Morgan, Jules. (2018) “Living Well with Dementia.” The Lancet Neurology, vol. 17, no. 4, pp. 306-307.

Nussbaum, Martha. (1992) "Human Functioning and Social Justice: In Defence of Aristotelian Essentialism." Political Theory, vol. 20, no. 2, May, pp. 202-246.

Null, Roberta L., and CRC Press. (2014) Universal Design: Principles and Models. CRC Press, Boca Raton, Fla. 
O’Brien, Gerald V. (2003) “People with Cognitive Disabilities: The Argument from Marginal Cases and Social Work Ethics.” Social Work, vol. 48, no. 3, July pp. $331-337$

Oliver, Michael. (2009) Understanding Disability. Palgrave Macmillan.

Patterson, Cynthia. (1985) "Not Worth the Rearing." Transactions of the American Philological Association (1974-2014), vol. 115, pp. 103-123.

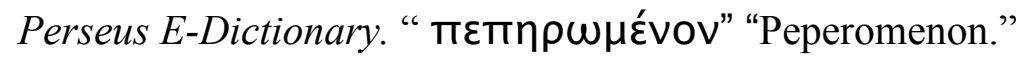
www.perseus.tufts.edu/hopper/resolveform. Accessed 21/08/2018.

“Princess Maru” (1942) Sensation Comics \#2, February Edition.

Russell, Bertrand. (1930) The Conquest for Happiness. Liverlight, New York/London, 1996.

Schuklenk, Udo. (2015) "Physicians can justifiably euthanize certain severely impaired neonates." The Journal of Thoracic and Cardiovascular Surgery, vol. 149, no. 2, February, pp. 535-537.

Sneed, Deborah. (2018) The Life Cycle of Disability in Ancient Greece. Unpublished dissertation.

Silvers, Anita and Leslie Pickering Francis. (2005) “Justice Through Trust: Disability and the 'Outlier Problem' in Social Contract Theory." Ethics, vol. 116, no. 1, October, pp. 40-76.

Simplican, Stacy Clifford. (2015) The Capacity Contract: Intellectual Disability and the Question of Citizenship. University of Minnesota Press. 
Simplican, Stacy Clifford. (2016) "Disavowals of Disability in Rawls' Theory of Justice and His Critics." Disability and Political Theory, edited by Barbara Arneil and Nancy J. Hirschman, Cambridge University Press, pp. 79-98.

Singer, Peter. (2011) Practical Ethics. Cambridge University Press.

Stone, Deborah. (2016) "Foreword." Disability and Political Theory, edited by Barbara Arneil and Nancy J. Hirschman, Cambridge University Press, pp. xii-xv.

The Sterilization of Leilani Muir. (1996) Directed by Glynis Whiting. Film Board of Canada.

Tessman, Lisa. (2005) Burdened Virtues: Virtue Ethics for Liberatory Struggles. Oxford University Press.

UN Convention on the Rights of Persons with Disabilities. (2006) www.un.org/development/desa/disabilities/convention-on-the-rights-of-personswith-disabilities.html. Accessed 21 ${ }^{\text {st }}$ August 2018.

Welsh, Moira and Randy Risling. (2018) "The Fix: One Peel nursing home took a gamble on fun, life and love.” Mississauga News, Mississauga, ON, 22 June.

Wilde, Oscar. (1891) The Soul of Man Under Socialism and Selected Critical Prose. Edited and Introduction by Linda Dowling. Penguin Classics, 2001.

World Health Organization (2011) World Report on Disability.

Van N. Viljoen, G. (1959) "Plato and Aristotle on the Exposure of Infants at Athens." Acta Classica, vol. 2, pp. 58-69.

Vukov, Joseph. (2017) "Personhood and Natural Kinds: Why Cognitive Status Need Not Affect Moral Status," The Journal of Medicine and Philosophy: A Forum for Bioethics and Philosophy of Medicine, vol. 42, no. 3, June, pp. 261-277. 
Young, Stella. (2014) "I am not your inspiration, thank-you very much.” TED Talks, June $14^{\text {th }}$. 